\title{
Imitation and price competition in a differentiated market
}

Citation for published version (APA):

Khan, A., \& Peeters, R. J. A. P. (2015). Imitation and price competition in a differentiated market. Maastricht University, Graduate School of Business and Economics. GSBE Research Memoranda No. 032 https://doi.org/10.26481/umagsb.2015032

Document status and date:

Published: 01/01/2015

DOI:

10.26481/umagsb.2015032

Document Version:

Publisher's PDF, also known as Version of record

\section{Please check the document version of this publication:}

- A submitted manuscript is the version of the article upon submission and before peer-review. There can be important differences between the submitted version and the official published version of record.

People interested in the research are advised to contact the author for the final version of the publication, or visit the DOI to the publisher's website.

- The final author version and the galley proof are versions of the publication after peer review.

- The final published version features the final layout of the paper including the volume, issue and page numbers.

Link to publication

\footnotetext{
General rights rights.

- You may freely distribute the URL identifying the publication in the public portal. please follow below link for the End User Agreement:

www.umlib.nl/taverne-license

Take down policy

If you believe that this document breaches copyright please contact us at:

repository@maastrichtuniversity.nl

providing details and we will investigate your claim.
}

Copyright and moral rights for the publications made accessible in the public portal are retained by the authors and/or other copyright owners and it is a condition of accessing publications that users recognise and abide by the legal requirements associated with these

- Users may download and print one copy of any publication from the public portal for the purpose of private study or research.

- You may not further distribute the material or use it for any profit-making activity or commercial gain

If the publication is distributed under the terms of Article $25 \mathrm{fa}$ of the Dutch Copyright Act, indicated by the "Taverne" license above, 


\section{Maastricht University}

Abhimanyu Khan, Ronald Peeters

Imitation and price competition in a differentiated market

$\mathrm{RM} / 15 / 032$

\section{GSBE}

Maastricht University School of Business and Economics

Graduate School of Business and Economics

P.O Box 616

NL- 6200 MD Maastricht

The Netherlands 


\title{
Imitation and price competition in a differentiated market
}

\author{
Abhimanyu Khan* Ronald Peeters ${ }^{\dagger}$
}

November 9, 2015

\begin{abstract}
We study the market outcome that evolves in the long-run when price-setting firms, that compete in a differentiated market, are driven by an imitation dynamic. We find that the prices that can evolve in the long-run depend on the level of market differentiation and on the degree of oversight firms have on market decisions and outcomes. The unique symmetric pure Nash equilibrium price is always supported in the long-run, and it is the unique long-run market outcome for high and low levels of differentiation, when there is no oversight or even with limited oversight on market decisions and outcomes. For intermediate levels of differentiation, in addition to the Nash equilibrium price, there is a set of prices that may emerge in the long-run: while these other prices are below Nash equilibrium price when there is (almost) no oversight on market performances, they are above Nash equilibrium price when the oversight on market performances is more acute.
\end{abstract} JEL Classification: C72, C73, D21, D43, L11, L13.

Keywords: differentiated markets; imitation; evolution; observability

${ }^{*}$ Cambridge-INET. E-mail: ak933@cam.ac.uk

${ }^{\dagger}$ Department of Economics, Maastricht University. E-mail: r.peeters@maastrichtuniversity.nl 


\section{Introduction}

In a seminal paper, Alchian (1950) suggests that profit maximisation may not be an accurate description of firm behavior, partly because it requires full information on the market structure, with precise knowledge of the demand curve being a prime example. Instead, Alchian argues that relative performance (or relative profit) may be a more realistic driver of firm behaviour. Assuming that firms are indeed motivated by relative profit, we posit that firms imitate the most profitable firm and investigate the market outcome that prevails in the long-run when such firms compete in prices in a differentiated market. ${ }^{1}$

In our model, a finite number of firms, that produce with constant marginal cost, are located equidistantly on a unit circle and compete for the consumers that are uniformly distributed over the circumference of the circle (a la Salop, 1979). We assume that firms follow an imitation dynamic, meaning that they imitate the price of the most profitable firm they observe. This leads to an absorbing state where all firms choose the same price, where the price depends on the initial conditions. We select amongst the absorbing states that this process may lead to on the basis of stochastic stability. Assuming that firms occasionally experiment with random prices enables the process to move from one absorbing state (of the imitation process without experimentations) to another. The states that are in the support of the invariant distribution of the resulting (Markov) process when the experimentation probability vanishes are relatively more difficult to transit from and easier to get in to; these will be more visible in the long run and we call them the stochastically stable states.

The unique symmetric pure Nash equilibrium price, which is a function of the level of market differentiation, serves as the benchmark for comparison of the (set of) prices that are supported in the long-run. In the Nash equilibrium, in a "highly" differentiated market, each firm chooses the monopoly price - a manifestation of the market power held by firms. In a "moderately" differentiated market, each firm chooses a "mutually non-aggressive" price that leaves no surplus for the marginal consumers. Finally, in a market with "low" differentiation, each firm prices at a mark-up above marginal cost, and this mark-up varies directly with the extent of market differentiation and inversely with the number of firms.

For the situation where there is no oversight on market outcomes, firms observe prices and profits of all other firms in the market (and imitation is based on complete observability), we find that when the level of market differentiation is high-enough or low-enough, the longrun stochastically stable outcome corresponds exactly with the (above) Nash equilibrium state. However, for an in-between range of differentiation, the set of stochastically stable

\footnotetext{
${ }^{1}$ Adoption of industry best practices serve as an example of imitative behaviour. In the academic literature, Huck et al. (1999), Offerman et al. (2002) and Apesteguia et al. (2007), amongst others, find experimental evidence of imitative firm behaviour on provision of feedback on strategies and profits.
} 
states contains, in addition to the Nash equilibrium state, a set of other states where the price chosen by the firms is lower than the Nash equilibrium price. Summarily, the Nash equilibrium is always supported as a long-run outcome, but it is the unique long-run outcome only when the market differentiation is high-enough or low-enough.

We investigate the robustness of the results obtained under complete observability when there is some oversight on market outcomes. We find that the results hold in toto when unobservability is minimal, i.e. when each firm may not observe at most one other firm. Next, we further limit observability of firms by considering an observability network where each firm observes all neighbours within a given distance, subject to an upper bound and a lower bound on this distance. ${ }^{2}$ We find that: (i) if the Nash equilibrium state is the unique stochastically stable state under complete observability (i.e. when market differentiation is high-enough or low-enough), the same holds under the assumed observability network, (ii) in addition, with the assumed observability network, the Nash equilibrium state is also uniquely stochastically stable for a range of market differentiation where this is not the case for complete observability $^{3}$, and (iii) for the remaining in-between range of market differentiation, the set of stochastically stable states contains the Nash equilibrium state, but now, in contrast to the complete observability situation, the price in the other states belonging to the stochastically stable set is higher than the Nash equilibrium price. These results firstly suggest the robustness of the Nash equilibrium state in an imitation based evolutionary model. Secondly, they imply that firms may benefit from having limited oversight on the market they are operating in, and that behaviour that may appear to be collusive may be actually generated by oversight on market outcomes.

This paper contributes to the existing literature on firm behaviour based on weaker informational assumptions in general, and imitation led firm behaviour in particular. In an influential paper, Vega-Redondo (1997) shows that the Walrasian equilibrium emerges as the unique long-run equilibrium when quantity-setting firms in a homogeneous market imitate the most profitable firm. This is extended by Tanaka (1999) to the case of asymmetric cost oligopolies: with two groups of firms, low cost and high cost, the stochastically stable state under imitation corresponds to the Walrasian output in each group of firms. On the other hand, Alós-Ferrer, Ania and Schenk-Hoppé (2000) study imitation by price-competing firms with decreasing returns to scale technology in a homogenous market and find that the long-run equilibrium supports a strict subset of the Nash equilibrium.

The focus on differentiated markets in our paper complements Tanaka (2000, 2001), which show that stochastically stable behaviour under price or quantity imitation coincides with the

\footnotetext{
${ }^{2}$ The upper bound on the distance is necessitated by the minimal unobservability result referred to earlier.

${ }^{3}$ That is, states with prices lower than the Nash equilibrium that were found to in the stochastically stable set under complete observability are no longer so under the observability network.
} 
unique finite-population evolutionary stable strategy in symmetrically differentiated oligopoly markets with a linear demand function, even when firms are asymmetric with respect to the cost of production. We contribute to this branch of the literature by the emphasis on spatial differentiation that captures the principle that a particular firm may be relatively more affected by the strategy of a subset of firms. This nuance is not captured in the differentiated market structure used in the earlier papers, but is conveniently encapsulated by the Salop circle - a firm is more affected by, and in turn affects to a greater extent, the immediately neighbouring firms. Our paper is most related to Khan and Peeters (2015), which analyses the long-run equilibrium under imitation in such a spatially differentiated market with firms setting both price and quantity, and finds that the stochastically stable state coincides uniquely with the Nash equilibrium. We postpone a comparative discussion of the current paper and Khan and Peeters (2015) to the concluding section.

In the next section we present the basic model. Subsequently, in Section 3, we present the Nash equilibrium outcome, the long-run outcome under complete observability, and the long-run outcome under incomplete observability. The main propositions are followed by the guiding intuitions that are structured by means of a series of remarks; formal proofs are presented in the (lengthy) appendix. In Section 4, we close with a short discussion.

\section{Model}

Let $n$ firms, with $n \geq 7$, be located equidistantly on a (Salop) circle of unit circumference. ${ }^{4}$ These firms choose their own price simultaneously and meet the demand that results from the profile of chosen prices by producing at constant marginal cost $c$. Consumers are distributed uniformly along the circumference. Each consumer observes the prices announced by the firms and purchases at most one unit of the good. The gross utility received on purchase equals $\beta$, and a linear transportation cost of $\tau$ per unit distance of distance traveled is incurred. The net utility of a purchase is the gross utility $(\beta)$ less the price set by, and the transportation cost to, the chosen firm, with the reservation utility of abstinence normalised to 0 . A consumer maximises utility and purchases only if the net utility from doing so is at least 0 , in which case, the firm providing the highest (non-negative) net utility is chosen. ${ }^{5}$

We follow Apesteguia and Selten (2005) and Khan and Peeters (2015) in describing the

\footnotetext{
${ }^{4}$ Even though this assumption is guided by our motivation to study a differentiated market, it is noteworthy that Hehenkamp and Wambach (2010) show that the equidistant locations of firms on a Salop circle is the predicted long-run outcome in a two-stage evolutionary model where firms choose location by imitation in the first stage, and choose the Nash equilibrium price corresponding to the first stage location profile in the second stage.

${ }^{5}$ When the maximum net utility that a consumer receives on purchase is exactly equal to 0 , we assume the good is purchased. If a consumer receives the maximum net utility (of at least zero) from more than one firm, each firm in contention has equal probability of being chosen.
} 
demand faced by a firm. Let $v \in[0,1)$ denote the circle coordinate and $v=\frac{i}{n}$ be the location of firm $i$. Let firm $i$ choose price $p_{i}$. The local price at a location $v$ is

$$
p(v)=\min _{i=1, \ldots, n}\left\{p_{i}+\tau \delta(v, i)\right\}
$$

where $\delta(v, i)$ is the distance between location $v$ and firm $i: \delta(v, i)=\min \left\{\left|v-\frac{i}{n}\right|, 1-\left|v-\frac{i}{n}\right|\right\}$.

If the local price at a location is larger than $\beta$, the demand from that location is zero. If the local price is less than or equal to $\beta$, the demand from that location is one, and in case more than one firms offer the same local price, the firms share the demand equally in probabilistic terms.

In this paper we will particularly deal with situations of the type where firm $i$ chooses price $p_{i}$ while all other firms choose the same price $p$. For this specific situation, the above expression for demand of firm $i$ can be written as

$$
d_{i}=\left\{\begin{array}{lll}
2 \frac{\beta-p_{i}}{\tau} & \text { if } \quad p_{i}>2 \beta-p-\frac{\tau}{n} \\
\frac{1}{\tau}\left(p_{i}-p+\frac{\tau}{n}\right) & \text { if } \quad p_{i} \leq 2 \beta-p-\frac{\tau}{n}
\end{array}\right.
$$

Firm $i$ receives a profit of $\pi_{i}=\left(p_{i}-c\right) \cdot d_{i}$.

We define a "marginal consumer" to be a consumer who either (a) receives a maximum net utility exactly equal to 0 , or (b) receives the same maximum non-negative utility from more than one firm, and so, is indifferent amongst these firms. Two or more firms are said to "compete for the marginal consumer" if they set prices such that there exists a consumer that receives the same maximum non-negative utility from these firms and is indifferent amongst them. A firm is said to have a segregated market if it does not compete for the marginal consumer.

\section{Results}

Our interest lies in the outcome that arises in the long-run when firms follow an imitation dynamic, with price being the decision variable. We study this in a framework of complete and incomplete observability, and benchmark the resulting outcome(s) to the Nash equilibrium.

\subsection{Nash equilibrium}

The following proposition presents the unique symmetric pure strategy Nash equilibrium for varying levels of the market differentiation parameter (the proof of which can be found in Khan and Peeters, 2015).

Proposition 1. (i) Suppose $\tau>n(\beta-c)$. In the unique symmetric pure strategy Nash equilibrium, all firms choose the monopoly price $p^{m}=\frac{\beta+c}{2}$. 
(ii) Suppose $\tau \in\left[\frac{2}{3} n(\beta-c), n(\beta-c)\right]$. In the unique symmetric pure strategy Nash equilibrium, all firms choose the price $p^{n}=\beta-\frac{\tau}{2 n}$.

(iii) Suppose $\tau<\frac{2}{3} n(\beta-c)$. In the unique symmetric pure strategy Nash equilibrium, all firms choose the price $p^{c}=c+\frac{\tau}{n}$.

Moreover, the Nash equilibria described above are strict.

The thick line in Figure 1 illustrates the Nash equilibrium price as a function of the market differentiation i.e. transportation cost parameter . The graph shows that this price is continuous in the transportation cost $\tau$. It increases with the transportation cost up to a value of $\tau=\frac{2}{3} n(\beta-c)$ from where it decreases to reach the monopoly price at $\tau=n(\beta-c)$, and settles there for higher values of the transportation costs.

When transportation costs are high as in area (i), firms are endowed with significant market power which manifests itself in the monopoly outcome. As transportation costs decrease to the range in area (ii), the firms price "non-aggressively" in the sense that they share the market while extracting all surplus from the marginal consumers, i.e. the consumers located exactly in between two firms receive a net utility of zero. Since in this range of transportation costs firms extract all surplus from the marginal consumers (whose utility is decreasing in the transportation cost) in a fully served market, the equilibrium price decreases with the transportation costs, implying that more market differentiation may lead to lower prices. As transportation costs drop beyond the threshold dividing area (ii) and (iii), the equilibrium price is given by a mark-up over marginal cost, with the mark-up decreasing in the level of differentiation.

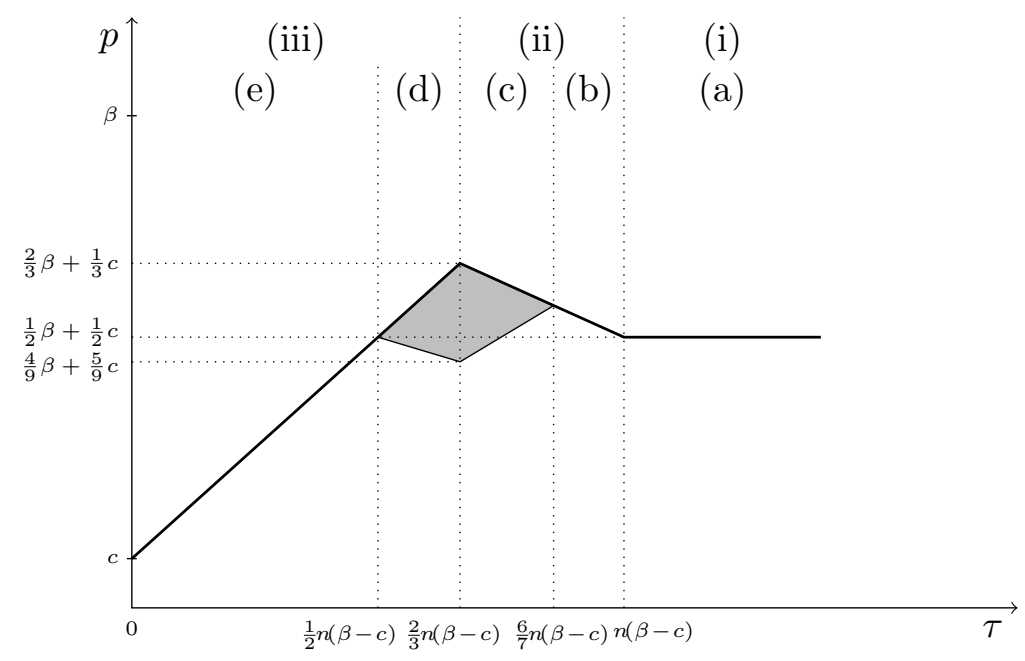

Figure 1: The thick line presents the Nash equilibrium price as a function of the transportation costs. This line together with the gray area represent the prices that are supported in the stochastically stable set as a function of the transportation costs. 
One important observation that will play a role in developing the intuition of the results to follow is that the Nash equilibrium price is a weak better-reply from all other symmetric strategy profiles. That is, from any strategy profile where all firms choose identical prices, if a firm experiments with the Nash equilibrium price, then it obtains at least as much profit as it was receiving earlier. ${ }^{6}$

\subsection{Imitation with complete observability}

In our imitation framework, firms choose price simultaneously from a finite grid of prices. The state, defined by the profile of prices $\left(p_{i}\right)_{i=1, \ldots, n}$, determines the demand faced and the profit received by each firm. The prices and profits of all firm are observed by all firms, and the most profitable firm is imitated by the others. When there is more than one imitable action (for example, when multiple firms are most profitable but with the use of disparate strategies), we assume there is an equal probability of each of the imitable actions being chosen. This describes the unperturbed process of imitation. ${ }^{7}$ A state is said to be absorbing when there is no possibility of transiting to another state. States where all firms choose identical prices are called monomorphic. According to the next proposition (proof in the appendix) these monomorphic states are precisely the absorbing states of the unperturbed process of imitation.

Proposition 2. The set of absorbing states consists precisely of all monomorphic states.

In order to select among these absorbing states, we augment the unperturbed imitation dynamic with the possibility of firms experimenting with their choice of price. This experimentation may be interpreted as a firm choosing its price on the basis of some consideration other than imitation of the most profitable firm. Each firm, with an independent probability $\varepsilon$, chooses a random price. As the proposition above states, without experimentation, the unperturbed imitation process would converge to (and would stay locked into) an absorbing state that depends on the initial profile of prices. Now, experimentation makes the transition from an absorbing state of the unperturbed imitation process to another possible. For example, starting from a monomorphic state, if a firm experiments with a particular price and on account of this, turns out to be the most profitable firm, the other firms imitate this experimenting firm, thereby causing a transition from the initial monomorphic state. ${ }^{8}$ The resulting experimentation-augmented imitation dynamic (or the perturbed process) has no absorbing

\footnotetext{
${ }^{6}$ See Khan and Peeters (2015) for details.

${ }^{7}$ For ease of exposition, we restrict attention to prices being at least equal to marginal cost (consideration of lower prices does not affect any of the results).

${ }^{8}$ Of course, the transition from an absorbing state of the unperturbed process may require more than one firm to experiment.
} 
states. Henceforth, whenever we mention absorbing states, we refer to the absorbing states of the unperturbed process.

Next, stochastic stability is determined by the relative ease of transiting in and transiting out of absorbing states. Absorbing states that are comparatively easiest to reach from the other absorbing states (i.e. needs 'fewer' experimentations) and most difficult to move out (i.e. needs 'more' experimentations) are the stochastically stable outcomes. ${ }^{9}$ The next proposition presents the stochastically stable outcomes for various levels of market differentiation (i.e. the transportation cost parameter). ${ }^{10}$

Proposition 3. (a) Suppose $\tau>n(\beta-c)$. In the stochastically stable state, all firms set the monopoly price $p^{m}=\frac{\beta+c}{2}$.

(b) Suppose $\tau \in\left(\frac{6}{7} n(\beta-c), n(\beta-c)\right]$. In the stochastically stable state, all firms set the price at $p^{n}=\beta-\frac{\tau}{2 n}$.

(c) Suppose $\tau \in\left[\frac{2}{3} n(\beta-c), \frac{6}{7} n(\beta-c)\right]$. The stochastically stable set consists of the monomorphic states where all firms set the same price $p \in\left[c+\frac{2 \tau}{3 n}, p^{n}=\beta-\frac{\tau}{2 n}\right]$.

(d) Suppose $\tau \in\left(\frac{1}{2} n(\beta-c), \frac{2}{3} n(\beta-c)\right]$. The stochastically stable set consists of the monomorphic states where all firms set the same price $p \in\left[\frac{2 \beta+c-\frac{\tau}{n}}{3}, p^{c}=c+\frac{\tau}{n}\right]$.

(e) Suppose $\tau<\frac{1}{2} n(\beta-c)$. In the stochastically stable state, all firms set the price at $p^{c}=c+\frac{\tau}{n}$.

A comparison of the stochastically stable set with the Nash equilibrium reveals that: (1) when the level of differentiation is high-enough (regions (a) and (b) in Figure 1 above), the stochastically stable set uniquely contains the Nash equilibrium state; (2) for in-between levels of differentiation (regions (c) and (d)), the stochastically stable set contains the Nash equilibrium state, along with a set of monomorphic states with lower price; and (3) for lowenough levels of differentiation (region (e)), the stochastically stable state uniquely contains the state where all firms price at the Nash equilibrium.

The proof (presented in the appendix) relies on the fact that it takes more experimentations to leave the set of states that the proposition claims to be stochastically stable than it takes for the process to reach this set of states from all other absorbing states. The proof makes use of two results from Ellison (2000). First, if it takes a (series of) single experimentation(s) to reach a set of absorbing states from any other absorbing state and more than one experimentation to exit this set, then the stochastically stable set is contained in this set of

\footnotetext{
${ }^{9}$ For more details, the reader is referred to Young (1993) or Kandori et al. (1993).

${ }^{10}$ Finiteness of the strategy space is a technical requirement for stochastic stability. Alós-Ferrer (2006) shows that in general, Nash equilibrium or other rest points properties of a continuous strategy space may not carry over to the discrete strategy case. However, even with a finite strategy space, the unique symmetric strict pure strategy Nash equilibrium does not change since choosing the prices described in Proposition 1 from any other monomorphic state is a weak better reply. In addition, the propositions related to stochastic stability do not assume continuity of action space. Thus, our results are not affected by discretisation of the action space.
} 
absorbing states. Second, suppose it has been established that the stochastically stable set is contained in a set of absorbing states consisting of at least two monomorphic states, $x$ and $y$; then, if it takes two experimentations to transit from $x$ to $y$ and vice-versa, then both these states are supported in the long-run outcome.

In the following we present the intuition behind the result stated in the proposition, with a particular focus on the long-run stability of the Nash equilibrium. The intuition is aided by two remarks. The first remark concerns the transition into the Nash equilibrium state from other absorbing states; the second pertains to transitions out of the Nash equilibrium state.

Remark 1. If the price in an initial monomorphic state is higher than the Nash equilibrium price, and a firm experiments with the Nash equilibrium price, then the experimentation firm is (one of) the most profitable firm(s) and so, imitation leads to the Nash equilibrium state. On the other hand, if the price of the initial state is lower, then the fate of the experimentation depends on the level of market differentiation.

Explanation: As the Nash equilibrium price is a (weak) better response from any monomorphic state, an experimentation by a firm with the Nash equilibrium price is weakly profitimproving for the experimenting firm. If this experimentation's effect on the other firms' profit is such that the most profitable non-experimenting firm is not more profitable than the experimenting firm, the experimentation is successful and imitation leads to the Nash equilibrium state.

When the price in the initial state is higher than the Nash equilibrium price, the profit of the non-experimenting firms remains the same at best (the neighbouring firms of the experimenting firm may experience lower profit due to a loss in demand). This makes the experimenting firm the most profitable, and imitation leads to the Nash equilibrium state. Thus, from a state where the price is higher than the Nash equilibrium, a single experimentation results in a transition to the Nash equilibrium state.

On the other hand, when the price in the initial state is lower than the Nash equilibrium price and a firm experiments with the Nash equilibrium price, the neighbouring firms' profit may increase as they face higher demand. This makes the evaluation of this experimentation slightly less obvious. Interestingly, the level of market differentiation plays a pivotal role in this calculus. When market differentiation is high-enough (i.e. $\tau>\frac{6}{7} n(\beta-c)$ ), the market power held by firms results in lower prices of the neighbouring firms not drawing away substantial consumers from the experimenting firm; here, the single firm experimentation with the Nash equilibrium price makes the experimenting firm the most profitable. However, for differentiation lower than that (i.e. $\tau \leq \frac{6}{7} n(\beta-c)$ ), such a single firm experimentation is not successful i.e. the lower price of the neighbouring firms draws enough consumers from the experimenting firm, so that the latter is not amongst the most profitable firms. However, 
we show in the proof that when two firms experiment, with one of the firms experimenting with the Nash equilibrium price, then the firm with the Nash equilibrium price is imitated on account of being the most profitable.

Remark 2. It is not possible to exit the Nash equilibrium state when only one firm experiments.

Explanation: As the Nash equilibrium is strict, any experimentation by a firm from the Nash equilibrium state is strictly profit-reducing for the experimenting firm. When the experimentation is with a higher price, the profit of the other firms do not decrease; in fact, the profit of the neighbouring firms may increase because of additional demand generated by the higher price of the experimenting firm. This results in the experimenting firm not being amongst the most profitable firms; in fact, imitation by the experimenting firm causes a reversion to the Nash equilibrium state. On the other hand, when a firm experiments with a lower price, it cannot affect the profit of all other firms. ${ }^{11}$ This, in particular, means that there exists a non-experimenting firm that continues to receive the Nash equilibrium profit. As the experimenting firm experiences a reduction in profit (due to the equilibrium being strict), the experimenting firm is less profitable than at least one non-experimenting firm, and it imitates the Nash equilibrium price causing a reversion to the Nash equilibrium state. So, irrespective of the level of differentiation, it is not possible to move out of the Nash equilibrium state with one experimentation.

The implication is that a transition from the Nash equilibrium state requires at least two experimentation firms. Importantly, it is possible to exit the Nash equilibrium state when two firms experiment only for the in-between range of market differentiation (i.e. $\left.\tau \in\left[\frac{1}{2} n(\beta-c), \frac{6}{7} n(\beta-c)\right]\right)$ but not for the low-enough differentiation $\left(\tau<\frac{1}{2} n(\beta-c)\right)$. The reason for this is that for low-enough differentiation, the Nash equilibrium price becomes competitive enough to withstand similar experimentations.

It can be gathered from the above that: (1) for high-enough differentiation $\left(\tau>\frac{6}{7} n(\beta-c)\right)$, it takes a single experimentation to transit into the Nash equilibrium state, but more than one experimentation to move out of it, making it the unique stochastically stable outcome; (2) for an in-between range of differentiation $\left(\tau \in\left[\frac{1}{2} n(\beta-c), \frac{6}{7} n(\beta-c)\right]\right)$, it takes at most two experimentations to transit into absorbing states in a set that contains the Nash equilibrium state along with other monomorphic states with lower prices, but more than two experimen-

\footnotetext{
${ }^{11}$ Denoting the Nash equilibrium price by $p^{*}$, it can be verified that even when a firm experiments with the lowest feasible price of marginal cost, while all other firms stick to $p^{*}$, then because $\beta-p^{*} \geq \beta-c-\frac{\tau}{n}$, the experimenting firm can at most attract the consumers up to the location of the neighbouring firm. The non-neighbouring firms (the existence of which is established by the assumption on the number of firms) are not affected as they do not cater to the consumer located at the position of the neighbouring firm of the experimenting firm.
} 
tations to move out of any state in this set; so, this set is supported in the long-run outcome; and (3) for low-enough differentiation $\left(\tau<\frac{1}{2} n(\beta-c)\right)$, it takes at most two experimentations to transit into the Nash equilibrium state, but more than two experimentations to move out of it, making it the unique stochastically stable outcome. ${ }^{12}$

As the least resistant path of transition into the Nash equilibrium state from any other state needs two experimentations for both in-between market differentiation and low market differentiation, the difference in the stability of the Nash equilibrium state for these two ranges of market differentiation is explained by differential ease of transition out of the Nash equilibrium state. To better understand the reason behind why the Nash equilibrium is the unique stochastically stable state for low market differentiation but not for in-between market differentiation, we elaborate on the nature of the two-firm experimentations that cause a transition out of the Nash equilibrium state in each of the two cases with the help of a series of remarks and explanations. In Remark 3, we argue that a transition from the Nash equilibrium (in either case) may occur only if the two experimenting firms are neighbours. In Remark 4, we reason that a transition from the Nash equilibrium (in either case) is not possible if both experimenting firms experiment with a price lower than the Nash equilibrium. In Remarks 5 and 6 , we explain that a transition from the Nash equilibrium (in either case) may be possible only if the experimenting firm with the lower price is the most profitable.

Remark 3. A two-firm experimentation may induce such a transition from the Nash equilibrium state only if the two experimenting firms are neighbours.

Explanation: Suppose to the contrary that the two experimenting firms are not neighbours. Then there is at least one firm that is unaffected by the experimentations, and so continues to receive the Nash equilibrium profit. ${ }^{13}$ Because there exists one non-experimenting firm that remains unaffected by the experimentation, the situation is not meaningfully different from a single firm experimenting, and we have already established that a single-firm experimentation does not induce such a transition. It is, however, important to note that even when two neighbouring firms experiment, there exists at least one non-experimenting firm that is unaffected by the experimentation and continues to receive the Nash equilibrium profit. But, the difference now is that experimentation by two neighbours may increase the profit of one of the experimenting firms to the extent of making it the most profitable. Hence, in what follows, we will concentrate on situations when the experimenting firms are neighbours.

\footnotetext{
${ }^{12}$ Apesteguia and Selten (2005) conduct an experimental study of price competition on the Salop circle, with parameter setting corresponding to what we call "low-enough" differentiation, and find that behaviour differs from the Nash equilibrium. We suggest this difference may be due to two factors: (i) there are at most five firms in the experiment, while we assume the presence of at least seven firms; (ii) each firm only observes its neighbours rather than the entire population of firms.

${ }^{13}$ This is because of the reasoning used in Footnote 11, and the number of firms $n \geq 7$.
} 
Remark 4. If both the neighbouring firms experiment with prices below the Nash equilibrium price, then none of the experimenting firms is most profitable, and so a transition out of the Nash equilibrium state is not possible.

Explanation: To see this, consider the more profitable of the two experimenting firms and call it the primary experimenting firm. Because the other experimenting firm prices below the Nash equilibrium price, the primary experimenting firm now receives a lower profit compared to the situation where the other experimenting firm would not have experimented (and stayed at the Nash equilibrium price). But even in the latter case (when the other experimenting firm stays at the Nash equilibrium price), the primary experimenting firm's profit does not exceed that of at least one non-experimenting firm (that obtains the Nash equilibrium profit on account of being unaffected by the experimentations). It follows that with the two firm experimentation, this experimenting firm's profit is even lower, and so it is not the most profitable firms. Thus, the experimentation is not imitated.

Remark 5. If two neighbouring firms experiment such that one of them experiments with a price below the Nash equilibrium price, and the other with a price above the Nash equilibrium price, then a transition from the Nash equilibrium state is possible only if the experimenting firm with the lower price is most profitable firm.

Explanation: Let us refer to the experimenting firm with the lower (higher) price as the primary (secondary) experimenting firm. Suppose first that only the secondary experimenting firm had been experimenting; under such a situation, we have already established (by Remark 2) that it is not the most profitable firm. Now, if one of its neighbouring firms (i.e the primary experimenting firm) experiments with an even lower price, the secondary experimenting firm's profit is even lower, and so it can never be most profitable. It follows that in this case, a transition from the Nash equilibrium state will occur only if the primary experimenting firm is the most profitable firm.

Remark 6. If both the neighbouring firms experiment with prices above the Nash equilibrium price, then a transition from the Nash equilibrium state is possible only if the experimenting firm with the lower price is a most profitable firm.

Explanation: Let us again refer to the experimenting firm with the lower (higher) price as the primary (secondary) experimenting firm. Suppose first that only the secondary experimenting firm experiments with a price higher than the Nash equilibrium price, while the primary experimenting firm (for the moment) prices at the Nash equilibrium level. We have argued (by Remark 2) that the secondary experimenting firm has a lower profit than an unaffected non-experimenting firm that obtains the Nash equilibrium profit. Importantly, the primary experimenting firm (which has not experimented yet) has a higher profit than the unaffected 
non-experimenting firm as the former faces higher demand due to one of its neighbours (i.e. the secondary experimenting firm) choosing a higher price. It follows that the primary experimenting firm is also more profitable than the secondary experimenting firm in this configuration of prices. Now, if we look at the difference of the profit between the two experimenting firms (i.e. the profit of the secondary experimenting firm less the profit of the primary experimenting firm) as a function of the price of the primary experimenting firm, then this profit difference is negative when the primary experimenting firm chooses the Nash equilibrium price, and zero (because of symmetry) when the primary experimenting chooses the same price as the secondary experimenting firm. This difference is also negative when the primary experimenting firm chooses a price in between the Nash equilibrium price and the price of the secondary experimenting firm, i.e. the primary experimenting firm is more profitable than the secondary experimenting firm. Hence, the experimenting firm with the lower price is the more profitable of the two experimenting firms, confirming the statement of the remark.

We gather from the above that a two-firm experimentation may induce a transition out of the Nash equilibrium state when market differentiation is in-between only if (a) the two experimenting firms are neighbours, (b) at least one of the experimenting firms experiments with a price higher than the Nash equilibrium price, and (c) if the experimenting firm with the lower price obtains the highest profit amongst all firms. Thus, to evaluate the fate of a two-firm experimentation, we have to compare the profit of the primary experimenting firm with that of the most profitable non-experimentation firm when both the experimenting firms are neighbours and at least one of the experimenting firms chooses a price higher than the Nash equilibrium. To identify the most profitable non-experimenting firm, we note that the higher price of the secondary experimenting firm results in its non-experimenting neighbour facing a higher demand in comparison to other non-experimenting firms. Consequently, this firm is the most profitable non-experimenting firm. Thus, the net result of the two-firm experimentation rests on a profit comparison between the experimenter with the lower price, and the non-experimenting neighbour of the secondary experimenting firm.

The key take-way now is that while it is possible for two neighbouring firms to experiment such that the primary experimenting firm is the most profitable firm only when market differentiation is in the in-between range, but not when it is in the low-enough range. The reason for this is that when two neighbouring firm experiment with prices higher than the Nash equilibrium price (as in the supposition of Remark 6), low-enough market differentiation increases the demand of the non-experimenting neighbour of the secondary experimenter to such an extent that it is the most profitable firm. On the other hand, when the primary experimenting firm experiments with a price lower than the Nash equilibrium price (as in 
the supposition of Remark 5), the competitiveness of the Nash equilibrium price results in the primary experimenter not receiving enough demand to make it most profitable firm; when market differentiation is low, the Nash equilibrium price, which varies directly with the market differentiation parameter, becomes increasingly competitive as market differentiation decreases. As a result, when market differentiation is low-enough, the Nash equilibrium state is more stable against two-firm-experimentations, resulting in it being the only state supported as the stochastically stable equilibrium. However, experimentations of this nature are able to induce a transition from the Nash equilibrium state when the level of differentiation is in-between as the analogous effects are not as potent; this gives rise to multiple states being supported in the long-run.

Finally, we point out that the increasing difficulty of transiting out the Nash equilibrium state as the Nash equilibrium price becomes more competitive is also reflected in another occurrence. Consider the differentiated market when $\tau \in\left(\frac{1}{2} n(\beta-c), \frac{2}{3} n(\beta-c)\right]$. Here, the Nash equilibrium price $c+\frac{\tau}{n}$ is increasing in $\tau$ while the stochastically stable set consists of the monomorphic states where all firms set the price at $p \in\left[\frac{2 \beta+c-\frac{\tau}{n}}{3}, p^{c}=c+\frac{\tau}{n}\right]$. The lowest price that is supported in the long-run is decreasing in $\tau$, implying that the set of prices supported in the long-run shrinks towards (or collapses to) the Nash equilibrium price as $\tau$ decreases. The import of this is that as $\tau$ decreases, the Nash equilibrium price also decreases and as the Nash equilibrium price becomes more competitive, the set of lower prices that can invade the Nash equilibrium state with the same ease (i.e. with two-firm experimentations) shrinks. ${ }^{14}$

\subsection{Imitation with incomplete observability}

The results presented so far have been based on the assumption of complete observability each firm observes all other firms, enabling imitation of the most profitable firm. In this subsection, we ascertain how robust the Nash equilibrium state is to imitation when observability is incomplete. If observability is partial or incomplete, each firm observes a subset of the set of firms. Consequently, we assume that firms imitate the most profitable firm observed (rather than the most profitable). This opens up the possibility that an experimentation which is successful under complete observability may now not be observed by all firms, potentially resulting in the strategy of the experimentation not spreading throughout the firm population. Vice versa, experimentations that are not successful globally may now be successful in local pockets, causing a subset of the firms to imitate the strategy of the experimentation.

\footnotetext{
${ }^{14} \mathrm{It}$ is in this sense that the case when $\tau \in\left(\frac{1}{2} n(\beta-c), \frac{2}{3} n(\beta-c)\right]$ is different from the case when $\tau \in\left(\frac{2}{3} n(\beta-c), \frac{6}{7} n(\beta-c)\right]$; in the latter case, the Nash equilibrium price is not increasing in $\tau$, and so we do not observe the effect of the set of prices supported in the long-run shrinking towards the Nash equilibrium price as $\tau$ decreases.
} 
The primary question is if the Nash equilibrium state is robust to imitation under partial observability.

First, we consider a situation of "minimal" unobservability, i.e. each firm does not observe at most one other firm. Then we have the next proposition, followed by a verbal proof.

Proposition 4. If each firm does not observe at most one firm, then Proposition 3 holds.

Explanation: Because the most profitable firm is observed and imitated by at least $n-2$ other firms, at least $n-1$ firms choose the same price in any state belonging to the absorbing set. First, consider transitions into the stochastically stable set defined in Proposition 3. If the type of experimentation that was successful in Proposition 3 occurs now with incomplete observability, it is observed to be successful, and imitated, by at least $n-2$ other firms.So, in the following state, all firms but one choose a price that is supported in the stochastically stable set. But this is akin to a state where a single firm experiments while all other firms choose a price supported in the stochastically stable set. As we have shown that it is not possible to exit a state in the stochastically stable set under complete observability with one experimentation, the firm that chooses a different price is strictly less profitable than the others. This firm then observes at least one other firm being more profitable with the use of a price supported in the stochastically stable set and imitates it. Thus, the number of experimentations needed to move into the stochastically stable set remains unchanged.

We now examine the transition from the stochastically stable set under complete observability. Consider the same experimentations that have been shown to be unsuccessful in causing a transition from a state in the stochastically stable set under complete observability. The fact that the experimentation is unsuccessful implies that there exists a non-experimenting firm that is the most profitable; here, this non-experimenting firm is observed by at least $n-2$ other firms. Thus, at most one firm imitates the experimenting price as it may not observe the most profitable experimenting firm and may instead observe the experimentation to be successful. But again, this resulting state is akin to a state where a single firm experiments while all other firms choose a price supported in the stochastically stable set. As it takes at least two experimentations to move out of the states in the stochastically stable set, this single firm is strictly less profitable. In addition, it observes a non-experimenting firm to be the most profitable and imitates the non-experimenting firm, reverting to the initial state. It follows that the number of experimentations needed to transit from the stochastically stable set does not decrease.

In comparison to the complete observability case, the number of experimentations to transit in to a state supported in the long-run does not change, and the number of experimentations to transit out of such states does not decrease, establishing the proposition.

While Proposition 4 establishes the robustness of the Nash equilibrium when unobservabil- 
ity is minimal, we now examine what happens if unobservability is more acute. We study this question in a structured observability network: we assume each firm observes at least the $k \geq \max \left\{2, \frac{n-4}{4}\right\}$ closest firms on either side (i.e. observes all firms within distance $\frac{k}{n}$ ), implying that each firm observes at least $2 k$ other firms. Moreover, firms beyond a distance of $\frac{n-1}{2 n}$ are not observed. ${ }^{15}$ This leads to the following proposition (proof in appendix):

Proposition 5. Suppose each firm observes the $k \in\left[\max \left\{2, \frac{n-4}{4}\right\}, \frac{n-1}{2}\right)$ closest neighbours on either side. Then the unique symmetric pure strategy Nash equilibrium is the unique stochastically stable state when $\tau<\frac{1}{2} n(\beta-c)$ or $\tau>\frac{2}{3} n(\beta-c)$. When $\tau \in\left[\frac{1}{2} n(\beta-c), \frac{2}{3} n(\beta-\right.$ $c)]$, monomorphic states with price in $\left[p^{c}, \frac{2 \beta+c}{3}\right]$ form the support in the stochastically stable set.

Figure 2 illustrates the Nash equilibrium price, and the price of the states supported in the long-run under both complete and incomplete observability, as a function of the market differentiation (i.e. the transportation cost parameter). The thick line shows the Nash equilibrium price. The line together with the gray (black) area represent the prices that are supported in the stochastically stable set under complete (incomplete) observability. The above proposition (and the accompanying figure) shows that the unique symmetric pure strategy Nash equilibrium state is always supported as a long-run outcome, and hence, is robust to the type of unobservability we analyse here. Further, it can be seen that in comparison to the complete observability case, the Nash equilibrium state emerges as the unique stochastically stable outcome for a wider range of levels of market differentiation, and the prices in the states that form the support of the stochastically stable set are higher when observability is incomplete.

To understand the content of this proposition, we begin by comparing the mechanics of imitation under complete and incomplete observability. With complete observability, the most profitable firm was observed and imitated by all other firms. This led to the proposition that the absorbing states are described by the monomorphic states. However, with incomplete observability, the globally most profitable firm is observed to be most profitable by only a subgroup of the firm population, which imitate it. But once a subgroup of firms imitate this price, it is no longer obvious that other firms will subsequently imitate it - in the new resulting state, a firm with the price that started out as an experimentation may not be the most profitable. This raises, apart from other questions, a question about the composition of the absorbing set, and if monomorphic states continue to be the only absorbing states. In Lemma 1 (proof in appendix), we show that it is indeed the case and that any nonmonomorphic state is transient and leads a monomorphic state.

\footnotetext{
${ }^{15}$ This implies that each firm does not observe at least two firms.
} 


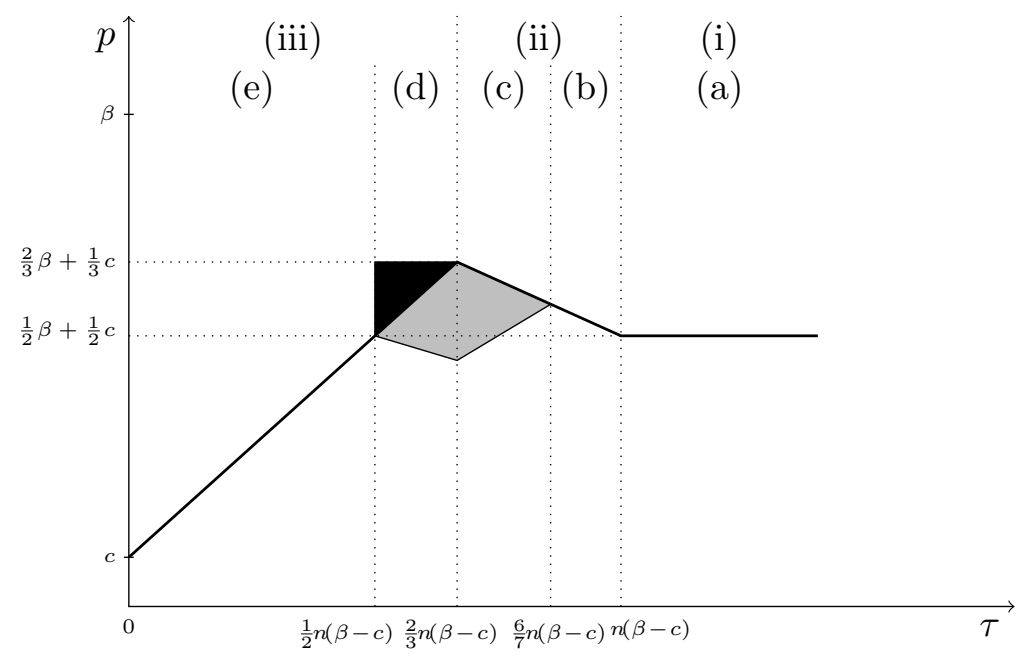

Figure 2: The thick line presents the Nash equilibrium price as a function of the transportation costs. This line together with the gray (black) area represent the prices that are supported in the stochastically stable set as a function of the transportation costs when observability is complete (incomplete).

Lemma 1. The monomorphic states are the only absorbing states of the imitation process under the defined observability structure.

This implies that we have to look into the relative ease of transiting into and the relative difficulty of transiting out of the monomorphic states to determine the stochastically stable set. With complete observability, an experimentation is unsuccessful (and hence not imitated) if the experimenting firm is not the most profitable amongst all firms. In general, with incomplete observability, it is possible that an experimentation may be imitated if a subgroup of firms observe the experimenting firm to be the most profitable in their respective neighbourhood, even though the experimenting firm is not the most profitable firm globally. However, the next remark (succeeded by an explanation) makes the point that if a single-firm experimentation was unsuccessful under complete observability, it is also unsuccessful under incomplete observability. Before doing so, we introduce additional notation: $\pi\left(p, p^{\prime}, p^{\prime \prime}\right)$ denotes the profit of a firm with price $p$ whose closest neighbour on one side chooses prices $p^{\prime}$ while the closest neighbour on the other side chooses price $p^{\prime \prime}$.

Remark 7. If a single-firm experimentation does not induce a transition from an absorbing state when observability is complete, then it also does not induce a transition when observability is incomplete.

Explanation: We use Figure 3 as an aid in arguing in favor of this remark. The figure shows the Salop circle with ten firms. Denoting the price of the experimenting firm (indicated by the grey node) by $p^{\prime}$ and the price of the other firms (the white nodes) by $p$, the 
experimenting firm obtains $\pi\left(p^{\prime}, p, p\right)$ while the non-experimenting firms obtain $\pi\left(p, p^{\prime}, p\right)$ or $\pi(p, p, p)$. As the experimentation is unsuccessful under complete observability, we know that $\pi\left(p^{\prime}, p, p\right)<\max \left\{\pi\left(p, p^{\prime}, p\right), \pi(p, p, p)\right\}$ holds. Under the assumed observability structure, each firm observes at least two firms on each side. The experimenting firm will be imitated only if it is observed by another firm as being the most profitable firm. Now, any firm (such as firm $i$, $i \in\{2,3,9,10\})$ that observes $\pi\left(p^{\prime}, p, p\right)$ also observes at least one instance of $\pi\left(p, p^{\prime}, p\right)$ and one instance of $\pi(p, p, p)$. As $\pi\left(p^{\prime}, p, p\right) \leq \max \left\{\pi\left(p, p^{\prime}, p\right), \pi(p, p, p)\right\}$, the experimenting firm is never imitated. For the same reason, the experimenting firm reverts to the price $p$ as it also observes firm 2 receiving $\pi\left(p, p^{\prime}, p\right)$ and firm 3 receiving $\pi(p, p, p)$. Thus, the experimentation does not induce a transition even when observability is incomplete.
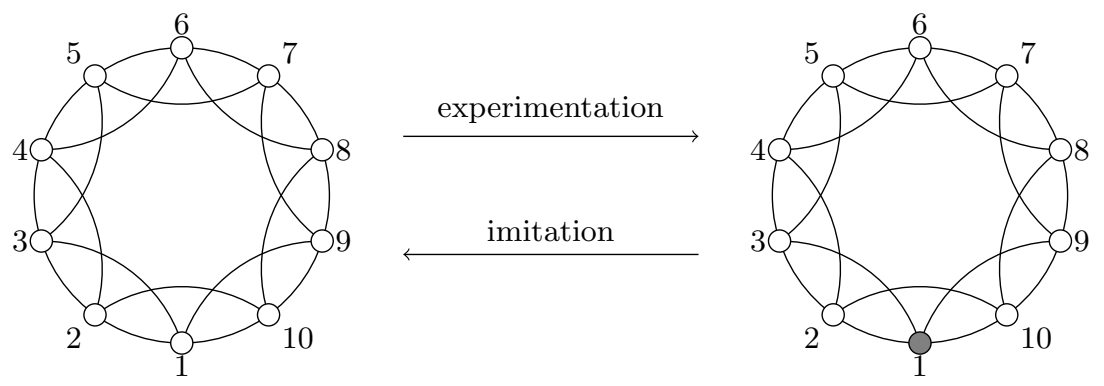

Figure 3: Figure supporting Remark 7.

Having established Remark 7, we now analyse how experimentations that are successful when observability is complete fare when observability is incomplete. If a single firm experimentation is successful under complete observability (i.e. the experimenting firm is the most profitable), it is observed and imitated by all other firms. Under our incomplete observability structure, this successful experimentation is observed and then imitated only by a subset of the firms. The question now is whether after the first wave of imitation, a firm ${ }^{16}$ that uses the experimenting price is observed to be the most profitable by the remaining firms (who persist with the old price)?

We answer this question in the following three remarks, which also help in developing some intuition for the difference between the stochastically stable outcome when observability is complete versus when it is incomplete. For all these remarks we use Figure 4, which shows ten firms, each of which observes the two closest firms on each side, as a visual aid. The experimenting firm(s) are depicted in grey, the firms that imitate to a different price in black and the firms which persist with the price of the initial monomorphic state in white.

\footnotetext{
${ }^{16}$ This refers not only to the initial experimenting firm but also includes firms which have imitated the experimenting firm.
} 


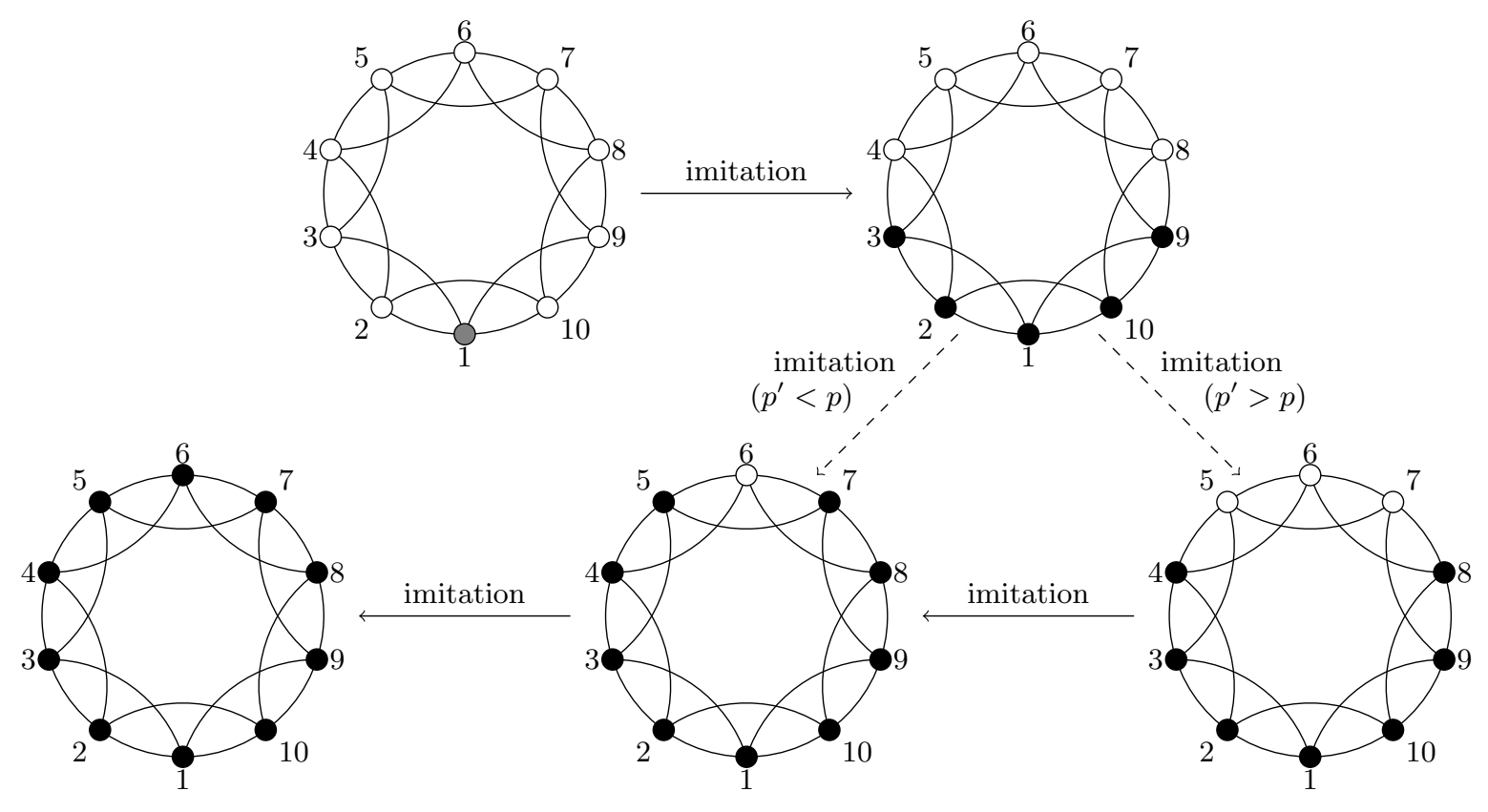

Figure 4: Figure supporting Remark 8, 9 and 10.

Remark 8. If a single-firm experimentation, where the experimenting firm chooses a higher price, is successful in inducing a transition from a monomorphic state when observability is complete, then it does the same when observability is incomplete.

Explanation: Consider a successful single firm experimentation with a higher price that is successful in causing a transition from states not supported in the stochastically stable set under complete observability to a state that is supported in the stochastically stable state under complete observability. Denoting the price of the experimenting firm (firm 1) by $p^{\prime}$ and the price of the other firms by $p$, the experimenting firm obtains $\pi\left(p^{\prime}, p, p\right)$ while the non-experimenting firms obtain $\pi\left(p, p^{\prime}, p\right)$ or $\pi(p, p, p)$. As the experimentation is successful under complete observability, $\pi\left(p^{\prime}, p, p\right) \geq \max \left\{\pi\left(p, p^{\prime}, p\right), \pi(p, p, p)\right\}$.

After the first wave of imitation, firms that choose the experimenting price $p^{\prime}$ obtain a profit of either $\pi\left(p^{\prime}, p^{\prime}, p^{\prime}\right)$ (firms 1, 2 and 10) or $\pi\left(p^{\prime}, p^{\prime}, p\right)$ (firms 3 and 9). The other firms obtain either $\pi\left(p, p^{\prime}, p\right)$ (firms 4 and 8 ) or $\pi(p, p, p)$ (firms 5,6 and 7 ). Now, a firm with price $p$ that observes $\pi\left(p^{\prime}, p^{\prime}, p^{\prime}\right)$ or itself receives $\pi\left(p, p^{\prime}, p\right)$ (such as firms 4 and 8), must observe the profit levels $\pi\left(p^{\prime}, p^{\prime}, p\right), \pi\left(p, p^{\prime}, p\right)$ and $\pi(p, p, p)$. Similarly, a firm with price $p^{\prime}$ that observes $\pi(p, p, p)$ or itself receives $\pi\left(p^{\prime}, p^{\prime}, p\right)$ (such as firms 3 and 9 ), must observe the profit levels $\pi\left(p, p^{\prime}, p\right), \pi\left(p^{\prime}, p^{\prime}, p\right)$ and $\pi\left(p^{\prime}, p^{\prime}, p^{\prime}\right)$. Since $p^{\prime}>p$, we have $\pi\left(p^{\prime}, p^{\prime}, p\right)<\pi\left(p^{\prime}, p^{\prime}, p^{\prime}\right)$. The firms that still choose price $p$ receive a profit of $\pi\left(p, p^{\prime}, p\right)$ or $\pi(p, p, p)$, and some of these firms (such as firms 4 and 8) observe $\pi\left(p^{\prime}, p^{\prime}, p\right)$. As $\pi\left(p^{\prime}, p^{\prime}, p\right) \geq \max \left\{\pi\left(p, p^{\prime}, p\right), \pi(p, p, p)\right\}$, these firms imitate the price $p^{\prime}$. By repeated iteration of this argument, $p^{\prime}$ spreads steadily 
to the entire population.

Remark 9. If a single-firm experimentation, where the experimenting firm chooses a lower price, is successful in inducing a transition from a monomorphic state when observability is complete, then it does the same when observability is incomplete if and only if $\pi\left(p^{\prime}, p^{\prime}, p\right) \geq$ $\pi(p, p, p)$.

Explanation: Consider successful single-firm experimentations with a lower price that were successful in causing a transition from states not supported in the stochastically stable set under complete observability to states that are supported in the stochastically stable set under complete observability. Let the price of the experimenting firm (firm 1) be $p^{\prime}$ and the price of the other firms be $p$, with $p^{\prime}>p$. As the experimentation is successful under complete observability, $\pi\left(p^{\prime}, p, p\right) \geq \max \left\{\pi\left(p, p^{\prime}, p\right), \pi(p, p, p)\right\}$. Under incomplete observability, $p^{\prime}$ is imitated by a subset of the firms (such as firms 2, 3, 9 and 10), which then receive a profit of either $\pi\left(p^{\prime}, p^{\prime}, p\right)$ or $\pi\left(p^{\prime}, p^{\prime}, p^{\prime}\right)$. Since $p^{\prime}<p$, we have $\pi\left(p^{\prime}, p^{\prime}, p\right) \geq \pi\left(p^{\prime}, p^{\prime}, p^{\prime}\right)$. The firms that still choose price $p$ receive a profit of either $\pi\left(p, p^{\prime}, p\right)$ or $\pi(p, p, p)$ with $\pi\left(p, p^{\prime}, p\right)<\pi(p, p, p)$. Now, any other firm (such as firm 4) will imitate $p^{\prime}$ if and only if $\pi\left(p^{\prime}, p^{\prime}, p\right) \geq \pi(p, p, p)$; this is the only circumstance under which a firm with price $p^{\prime}$ is observed by a firm with price $p$ to be the most profitable. Thus if this holds, then by iteration of the same reasoning, the single firm experimentation is successful with incomplete observability. On the other hand, if $\pi\left(p^{\prime}, p^{\prime}, p\right)>\pi(p, p, p)$, the firms with price $p^{\prime}$ (starting first with firms 3 and 9 , followed in the next round by the firms 1 and 2) revert to the use of price $p$.

Remark 10. Suppose the price in the initial monomorphic state and the experimenting price are such that the experimenting firm does not compete for the marginal consumer with its neighbours. If a single-firm experimentation, where the experimenting firm chooses a lower price, is successful in inducing a transition from a monomorphic state when observability is complete, then it does the same when observability is incomplete.

Explanation: While Remark 9 places a conditionality on when single-firm experimentations with a lower price that are successful under complete observability are also successful when observability is incomplete, Remark 10 states that incomplete observability is not an issue if there is no competition for the marginal consumer. To understand why, we add to the arguments for Remark 9 by now supposing that $p$ and $p^{\prime}$ are such that none of the firms compete for the marginal consumer. ${ }^{17}$ Then, all firms with price $p^{\prime}$ are equally profitable, i.e. $\pi\left(p^{\prime}, p^{\prime}, p\right)=\pi\left(p^{\prime}, p^{\prime}, p^{\prime}\right)$, and similarly, all firms with price $p$ are equally profitable, i.e.

\footnotetext{
${ }^{17}$ The remark only supposes that the experimenting firm does not compete for the marginal consumers with its neighbouring firms. However, since the experimenting firm has a lower price, the experimenting firm not competing for the marginal consumer implies that the same holds for the non-experimenting firms. Hence, in this case, none of the firms compete for the marginal consumer.
} 
$\pi\left(p, p^{\prime}, p\right)=\pi(p, p, p)$. Hence the condition $\pi\left(p^{\prime}, p^{\prime}, p\right) \geq \pi(p, p, p)$ in Remark 9 is equivalent to $\pi\left(p^{\prime}, p, p\right) \geq \max \left\{\pi\left(p, p^{\prime}, p\right), \pi(p, p, p)\right\}$; this last inequality holds because the single firm experimentation is successful with complete observability. So, $p^{\prime}$ is imitated iteratively till it is adopted by all firms.

Remark 11. If a two-firm experimentation, where two neighbouring firms experiment with the same price, is successful in inducing a transition from a monomorphic state when observability is complete, then it does the same when observability is incomplete.

Explanation: To ease comprehension, we use Figure 5, which shows ten firms, each of which observes the two closest firms on each side, as an aid. The experimenting firms are depicted with in grey, the firms that imitate to a different price are in black and the firms which persist with the price of the initial monomorphic state are in white. Consider a two-firm experimentation where the two neighbouring firms (firms 1 and 2) experiment with the same price $p^{\prime}$, which results in a transition into a state supported by the stochastically set under complete observability, implying $\pi\left(p^{\prime}, p^{\prime}, p\right)>\max \left\{\pi(p, p, p), \pi\left(p, p^{\prime}, p\right)\right\}$. Under incomplete observability, a subset of firms observes the successful experimentation and imitate $p^{\prime}$. These firms receive either $\pi\left(p^{\prime}, p^{\prime}, p\right)$ (firms 4 and 9) or $\pi\left(p^{\prime}, p^{\prime}, p^{\prime}\right)$ (firms 1, 2, 3 and 10). All firms that receive $\pi\left(p, p^{\prime}, p^{\prime}\right)$, such as firms 5 and 8 , and some of the firms that receive $\pi(p, p, p)$, such as firms 6 and 7 observe another firm receiving a profit equal to $\pi\left(p^{\prime}, p^{\prime}, p\right)$. Since $\pi\left(p^{\prime}, p^{\prime}, p\right)>\max \left\{\pi(p, p, p), \pi\left(p, p^{\prime}, p\right)\right\}$, these firms with price $p$ that observe another firm receiving a profit equal to $\pi\left(p^{\prime}, p^{\prime}, p\right)$ imitate $p^{\prime}$. In addition, none of the firms that chose $p^{\prime}$ change their price. By iteration of this reasoning, $p^{\prime}$ spreads to the all the firms and so, such an experimentation is successful even under incomplete observability.

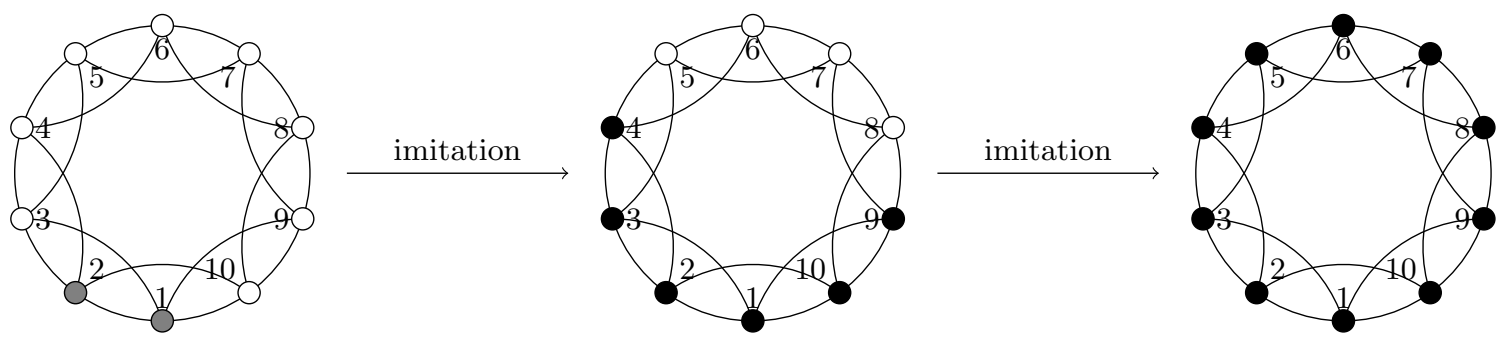

Figure 5: Figure supporting Remark 11.

Remark 12. If a two-firm experimentation, where two neighbouring firms experiment with different prices, is successful in inducing a transition from a monomorphic state when observability is complete, then it does the same when observability is incomplete if and only if $\max \left\{\pi\left(p^{\prime}, p^{\prime}, p^{\prime}\right), \pi\left(p^{\prime}, p^{\prime}, p\right)\right\}>\max \left\{\pi\left(p, p^{\prime}, p\right), \pi(p, p, p)\right\}$, where $p^{\prime}$ is the price of the more profitable experimenting firm. 
Explanation: To ease comprehension, we use Figure 6, which shows ten firms, each of which observes the two closest firms on each side, as an aid. The experimenting firms are depicted in grey, the firms that imitate to a different price are in black and the firms which persist with the price of the initial monomorphic state are in white. Consider a two-firm experimentation where the experimenting firms are neighbours (firms 1 and 2) and experiment with different prices $p^{\prime}$ and $p^{\prime \prime}$ respectively that was successful under complete observability in causing a transition into a state supported by the stochastically stable set. Assume the firm experimenting with price $p^{\prime}$ (firm 1) is the more profitable experimenting firm. Under incomplete observability, $p^{\prime}$ is imitated by a subset of the firms (firms 2, 3, 9 and 10), including the other experimenting firm. Whether $p^{\prime}$ will spread beyond the first imitation wave depends on if $\max \left\{\pi\left(p^{\prime}, p^{\prime}, p^{\prime}\right), \pi\left(p^{\prime}, p^{\prime}, p\right)\right\}>\max \left\{\pi\left(p, p^{\prime}, p\right), \pi(p, p, p)\right\}$. Since $\pi\left(p^{\prime}, p^{\prime}, p^{\prime}\right)>\pi\left(p^{\prime}, p^{\prime}, p\right)$ and $\pi\left(p, p^{\prime}, p\right)>\pi(p, p, p)$ if $p^{\prime}>p$, and $\pi\left(p^{\prime}, p^{\prime}, p^{\prime}\right)<\pi\left(p^{\prime}, p^{\prime}, p\right)$ and $\pi\left(p, p^{\prime}, p\right)<\pi(p, p, p)$ if $p^{\prime}<p$, the price $p^{\prime}$ will spread beyond the first imitation wave if $\pi\left(p^{\prime}, p^{\prime}, p^{\prime}\right) \geq \pi\left(p, p^{\prime}, p\right)$ if $p^{\prime}>p$ and $\pi\left(p^{\prime}, p^{\prime}, p\right) \geq \pi(p, p, p)$ if $p^{\prime}<p$. Otherwise, there is a gradual imitation led reversion to the state where all firms choose $p$.

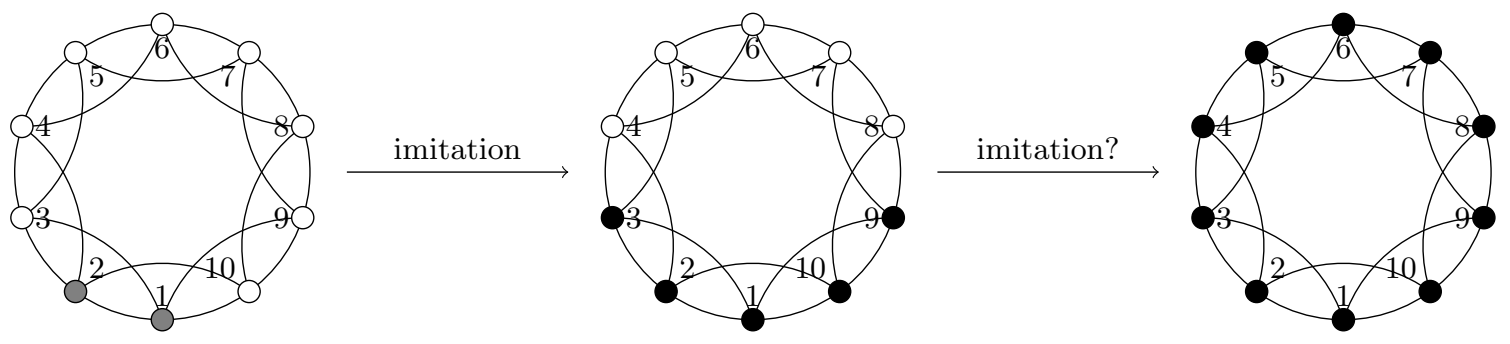

Figure 6: Figure supporting Remark 12.

The remarks above not only contrast imitation based on complete and incomplete observability, but also provide some intuition for the results obtained in Proposition 5. Transitions from monomorphic states where firms price below the Nash equilibrium price is possible with the same number of experimentations (Remark 8), but it is more difficult to transit into these states with price lower than the Nash equilibrium price (Remark 9). This is why monomorphic states where the firms' price is below the Nash equilibrium are no longer stochastically stable when observability is incomplete. At the same time, it is more difficult to transit from a set of monomorphic states where the firms' price is higher than the Nash equilibrium price (Remark 9). As a result, for an in-between range of the market differentiation, a set of monomorphic states with price higher than the Nash equilibrium are also stochastically stable.

Proposition 5 also makes the point that, in case of a regular observability network where each firm observes the same number of other firms, it is not possible to generalise the conclu- 
sion of Proposition 4 beyond the latter's stated premise. In other words, if each firm does not observe at most two firms (rather than 'at most one firm', as stated in Proposition 4), the results of Proposition 3 do not necessarily hold. However, perhaps most interestingly, incomplete observability of the type that we have analysed is actually profit-improving for the firms for two reasons. Firstly, the Nash equilibrium is the unique stochastically stable state for a larger range of the market differentiation parameter, implying that prices lower than the Nash equilibrium that would be expected under complete observability are no longer expected to be realised in the long-run. Secondly, for the range of market differentiation where the Nash equilibrium is not the unique long-run prediction, prices are higher than in Nash equilibrium may be expected to be realised. Thus, behaviour that may appear to be collusive may be actually generated by imitation in an incomplete observability environment.

\section{Conclusion}

In this paper, we analyse the long-run stochastically stable outcome when price-competing firms in a (spatially) differentiated market adopt the price of the most profitable firm observed. The stochastically stable outcome corresponds exactly with the unique symmetric pure strategy Nash equilibrium state when the level of market differentiation is high-enough or low-enough, irrespective of observability being complete or incomplete. For an in-between range of market differentiation, the unique symmetric pure strategy Nash equilibrium state is always contained in the stochastically stable set, along with a set of other states. While under complete observability, in these other states, firms may choose prices lower than the Nash equilibrium price, under incomplete observability firms may choose prices that are higher than the Nash equilibrium price. The first implication of our results is the robustness of the Nash equilibrium state in an imitation based evolutionary model. Secondly, firms may benefit from

limited observability in the market they are operating in, and behaviour that may appear to be collusive may be actually generated by incomplete observability of market outcomes.

The results herein make for an interesting comparison with Khan and Peeters (2015), who also study the long-run market outcome of the same imitation dynamic (under complete observability only), but with the crucial difference being firms set both price and quantity. The main finding there is that the stochastically stable outcome corresponds exactly with the unique symmetric pure strategy Nash equilibrium. In contrast to the results here, the most important distinction is that states with lower prices are not contained in the stochastically stable set for an in-between range of market differentiation. The reason for the Nash equilibrium state being more stable in the price-quantity model rests on the ease of transiting into this state from other states with lower prices. To elaborate, suppose that firms are in a (monomorphic) state with a price lower than the Nash equilibrium price. If a firm experiments 
with the Nash equilibrium price in a model with price and quantity choice, the neighbouring firms face excess demand on account of not being able to scale up production. As a result, the neighbouring firms earn the same profit as before the experimentation, whereas, if the firms choose quantity after observing the demand (as in the current paper), the neighbouring firms would experience a higher profit. The implication is that the firm which experiments with the Nash equilibrium price has to earn a higher profit when quantity is chosen after demand realisation (relative to when both price and quantity are chosen) for it to be imitated on grounds of being the most profitable firm. Consequently, the transition from states with a lower price to the Nash equilibrium state is relatively more difficult when firms choose quantity after demand realisation, giving rise to the result that these states with lower prices are also in the stochastically stable set. Thus, the flexibility in production afforded to firms when they produce after observing the demand is actually profit-deteriorating for the firms as it weakens the Nash equilibrium and allows for lower prices to be supported in the long-run.

\section{References}

1. Alchian A (1950). Uncertainty, evolution, and economic theory. Journal of Political Economy 58 (3): 211-221.

2. Alós-Ferrer C (2006). The discretisation of continuum strategy spaces. International Game Theory Review 8 (3): 499-514.

3. Alós-Ferrer C, A Ania and KR Schenk-Hoppé (2000). An evolutionary model of Bertrand oligopoly. Games and Economic Behavior 33 (1): 1-19.

4. Apesteguia J and R Selten (2005). Experimentally observed imitation and cooperation in price competition on the circle. Games and Economic Behaviour 51 (1): 171-192.

5. Apesteguia J, S Huck and J Oechssler (2007). Imitation: Theory and experimental evidence. Journal of Economic Theory 136 (1): 217-235.

6. Ellison G (2000). Basins of attraction, long run stochastic stability, and the speed of step-by-step evolution. Review of Economic Studies 67 (1): 17-45.

7. Hehenkamp B and A Wambach (2010). Survival at the center - The stability of minimum differentiation. Journal of Economic Behavior and Organization 76 (3): 853-858.

8. Huck S, HT Normann and J Oechssler (1999). Learning in Cournot oligopoly - An experiment. Economic Journal 109 (454): C80-C95.

9. Kandori M, GJ Mailath and R Rob (1993). Learning, mutation, and long-run equilibria in games. Econometrica 61 (1): 29-56. 
10. Khan $\mathrm{A}$ and $\mathrm{R}$ Peeters (2015). Imitation by price and quantity setting firms in a differentiated market. Journal of Economic Dynamics and Control 53: 28-36.

11. Offerman T, J Potters and J Sonnemans (2002). Imitation and belief learning in an oligopoly experiment. Review of Economic Studies 69 (4): 973-997.

12. Salop S (1979). Monopolistic competition with outside goods. The Bell Journal of Economics 10 (1): 141-156.

13. Tanaka Y (1999). Long run equilibria in an asymmetric oligopoly. Economic Theory $14(3)$ : 705-715.

14. Tanaka Y (2000). Stochastically stable states in an oligopoly with differentiated goods: equivalence of price and quantity strategies. Journal of Mathematical Economics 34 (2): 235-253.

15. Tanaka Y (2001). Evolution to equilibrium in an asymmetric oligopoly with differentiated goods. International Journal of Industrial Organisation 19 (9): 1423-1440.

16. Vega-Redondo F (1997). The evolution of Walrasian behavior. Econometrica 65 (2): 275-284.

17. Young HP (1993). The evolution of conventions. Econometrica 61 (1): 57-84. 


\section{Appendix}

\section{Proof of Proposition 2}

A monomorphic state is clearly absorbing as firms choose the same strategies and receive equal profits - this leaves no further scope for imitation. On the other hand, if we are in a state where the most profitable firm is unique, imitation by the other firms leads to a monomorphic state firms. If multiple firms realise the highest profit with disparate actions, the positive probability of imitation makes this state transient. Thus, from a non-monomorphic state, the process converges to a monomorphic state in finite time.

\section{Proof of Proposition 3}

Statement (a): $\tau>n(\beta-c)$.

First, in Part (i), we show that it takes a single experimentation to reach the state where all firms set their price at $p^{m}=\frac{\beta+c}{2}$. Next, in Part (ii), we show that it requires more than a single experimentation to transit out of that state.

Part (i). Suppose we are in an absorbing state where each firm chooses the price $p \neq p^{m}$ and receives the profit $\pi$. If a firm experiments with the Nash equilibrium price $p^{m}$, its firm's profit is at least $\pi$ as the Nash equilibrium price is a better response from any other monomorphic state. The firms that are not the closest neighbours of the experimenting firm are not affected by this experimentation and hence, are not more profitable than the experimenting firm. In addition, if $p \geq 2 \beta-p^{m}-\frac{\tau}{n}$, the two closest neighbouring firms (one on each side of the experimenting firm) are not affected either, resulting in the experimenting firm being the most profitable firm. Otherwise, when $p<2 \beta-p^{m}-\frac{\tau}{n}$, these two neighbouring firms are affected by the experimentation. The demand of each of these two neighbouring firms from the population lying between their location and that of the experimenting firm is $\frac{p^{m}-p+\frac{\tau}{n}}{2 \tau}$, while the demand from the consumers lying between their location and that of their respective non-experimenting neighbouring firm equals $\frac{1}{2 n} \cdot{ }^{18}$ So, each of these two neighbouring firms receive profit $\pi^{n}=\left(\frac{p^{m}-p+\frac{\tau}{n}}{2 \tau}+\frac{1}{2 n}\right)(p-c)$. The demand faced by the experimenting firm is $\left(\frac{p-p^{m}+\frac{\tau}{n}}{\tau}\right)$, and so its profit equals $\pi^{e}=\frac{p-p^{m}+\frac{\tau}{n}}{\tau}\left(p^{m}-c\right)$. It is easily derived that $\pi^{e} \geq \pi^{n}$ if and only if

$$
\left(p^{m}-c\right)\left(2 c+2 \frac{\tau}{n}-\beta-p\right) \geq 0 .
$$

The restriction $p<2 \beta-p^{m}-\frac{\tau}{n}$ together with $\tau>n(\beta-c)$ implies that the first term is positive. Moreover, $\tau>n(\beta-c)$ implies that the second term is positive at $p=2 \beta-p^{m}-\frac{\tau}{n}$, and so it is also positive for all lower values of $p$. Thus, the profit of the experimenting

\footnotetext{
${ }^{18} p<2 \beta-p^{m}-\frac{\tau}{n}$ and $\tau>n(\beta-c)$ together imply $p<\beta-\frac{\tau}{2 n}$. Hence, when two neighbouring firm price at $p<\beta-\frac{\tau}{2 n}$, each firm receives a demand equal to $\frac{1}{2 n}$ from the consumers situated in between them.
} 
firm is higher than that of its neighbours. Combined with the earlier observation that the experimenting firm is at least as profitable as the other non-experimenting firms (that are not the closest neighbours of the experimenting firm), we conclude that the experimenting firm belongs to the set of most profitable firms. Imitation of the experimenting firm leads to the state where all firms set their price at $p^{m}$.

Part (ii). This follows directly from Remark 2.

Statement (b): $\tau \in\left(\frac{6}{7} n(\beta-c), n(\beta-c)\right]$.

First, in Part (i), we show that it takes a single experimentation to reach the state where all firms set their price at $p^{n}=\beta-\frac{\tau}{2 n}$. Next, in Part (ii), we show that it requires more than a single experimentation to transit out of that state.

Part (i). Because of Remark 1, we only need to consider the transition to the Nash equilibrium state from other monomorphic states where the price is lower than the Nash equilibrium price. At all such monomorphic states (with $p<p^{n}$ ), the firms compete for the marginal consumer, and face identical demand of $\frac{1}{n}$. Suppose we are in such a state. When a firm experiments with the price $p^{n}$, it faces a demand of $\frac{p-p^{n}+\frac{\tau}{n}}{\tau}$. The demand of the firms that are not the closest neighbours of the experimenting firm does not change, and they continue to receive the same profit as before the experimentation. Because the Nash equilibrium price is a weak-better response from any other monomorphic state, these non-experimenting firms are not more profitable than the experimenting firm. So, we only need to compare profits of the experimenting firm with that of its closest neighbour. The demand of this closest neighbouring firm has two components: one coming from the population lying in the direction of the experimenting firm (equal to $\frac{p^{n}-p+\frac{\tau}{n}}{2 \tau}$ ), and one coming from the population lying in the direction of the non-experimenting neighbouring firm (equal to $\frac{1}{2 n}$ ). So, the profit of the neighbouring firm equals $\pi^{n}=\left(\frac{p^{n}-p+\frac{\tau}{n}}{2 \tau}+\frac{1}{2 n}\right)(p-c)$, while that of the experimenting firm equals $\pi^{e}=\frac{p-p^{n}+\frac{\tau}{n}}{\tau}\left(p^{n}-c\right)$. It is easily derived that $\pi^{e} \geq \pi^{n}$ if and only if

$$
\left(p^{n}-p\right)\left(3 c+3 \frac{\tau}{n}-2 \beta-p\right) \geq 0 .
$$

The first term is positive by assumption. The condition $\tau>\frac{6}{7} n(\beta-c)$ implies that the second term is positive at $p=p^{n}$. As this term is decreasing in $p$, it is positive for all $p<p^{n}$. It follows that the profit of the experimenting firm exceeds that of closest neighbouring firms, and that the experimenting firm is the most profitable firm in the market, due to which it is imitated by all other firms.

Part (ii). This follows directly from Remark 2. 
Statement (c): $\tau \in\left[\frac{2}{3} n(\beta-c), \frac{6}{7} n(\beta-c)\right]$.

In Part (i), we will show that it takes a single experimentation to reach $\Omega_{1}$, the absorbing set described by the monomorphic states where the price $p$ is in the interval $\left[c+\frac{2 \tau}{3 n}, p^{n}\right]$, where $p^{n}=\beta-\frac{\tau}{2 n}$. Part (ii) shows it takes more than one experimentation to move out of any state in $\Omega_{1}$. This establishes that the stochastically stable set is contained in $\Omega_{1}$. The fact that all monomorphic states in $\Omega_{1}$ are stochastically stable is demonstrated in Part (iii), by showing that it is possible to move between any two monomorphic states in this set with two experimentations.

Part (i). First, suppose we are in an absorbing state where each firm chooses the price $p>p^{n}$. Then, an experimentation by a firm with $p^{n}$ leads to this firm obtaining the highest profit, and imitation leads immediately into the set $\Omega_{1}$ (recall Remark 1). So now, suppose we are in an absorbing state where each firm chooses the price $p<c+\frac{2 \tau}{3 n}$. Let a firm experiment with $p^{\prime}=c+\frac{2 \tau}{3 n}$, due to which its profit equals $\pi^{e}=\left(p^{\prime}-c\right)\left(\frac{p-p^{\prime}+\frac{\tau}{n}}{\tau}\right)$. Importantly, the closest neighbouring firms of the experimenting firm (one on each side of the experimenting firm) are most profitable amongst the non-experimenting firms as the former attracts additional consumers (due to the higher price of the experimenting firm) and so, sell larger quantities at the same price (in comparison to the other non-experimenting firms). Hence, we only need to compare the profit of the experimenting firm with the profit of its closest neighbours to verify the success of the experimentation. The profit of such a firm is $\pi^{n}=(p-c)\left(\frac{p^{\prime}-p+\frac{\tau}{n}}{2 \tau}+\frac{1}{2 n}\right)$. It is easily derived that $\pi^{e} \geq \pi^{n}$ if and only if $\left(p-c-\frac{2 \tau}{3 n}\right)^{2} \geq 0$. As this inequality is satisfied by supposition, imitation of price $c+\frac{2 \tau}{3 n}$ leads into $\Omega_{1} \cdot{ }^{19}$

Part (ii). First, suppose we are in an absorbing state where all firm choose the same price $p \in\left[c+\frac{2 \tau}{3 n}, p^{n}\right]$.

Step 1. Let a firm experiment with $p^{\prime}>p^{n}$. Then, two possible situations can arise: one where the experimenting firm does not compete for the marginal consumer with its closest neighbouring firm (here $p^{\prime}>2 \beta-p-\frac{\tau}{n}$ ), and one where it does (here $p^{\prime} \leq 2 \beta-p-\frac{\tau}{n}$ ). In both cases, as the experimentation is with a higher price, the closest neighbour firms of the experimenting firm are the most profitable amongst non-experimenting firms. The difference in profit between the experimenting firm and its closest neighbour in case they compete for the marginal consumer equals

$$
\left(p^{\prime}-c\right)\left(\frac{p-p^{\prime}+\frac{\tau}{n}}{\tau}\right)-(p-c)\left(\frac{p^{\prime}-p+\frac{\tau}{n}}{2 \tau}+\frac{1}{2 n}\right)=\frac{1}{2 \tau}\left(p-p^{\prime}\right)\left(2 p^{\prime}+p-3 c-2 \frac{\tau}{n}\right) .
$$

The first term $\left(p-p^{\prime}\right)$ is negative by assumption. The second term is positive under the assumptions on $\tau$ and given $p \geq c+\frac{2 \tau}{3 n}, p \leq \beta-\frac{\tau}{2 n}$ and $p^{\prime}>p .{ }^{20}$ Thus, the experimenting

\footnotetext{
${ }^{19}$ Remark: Replace $p^{n}$ by $p^{c}$, and this part is applicable verbatim for the proof of Statements (d) and (e).

${ }^{20}$ Remark: This part of the proof also shows that it is not possible to transit from one monomorphic state in $\Omega_{1}$ with price $p$ to another state in $\Omega_{1}$ with a higher price $p^{\prime}>p$. Given the restriction on $\tau$, when all
} 
firm is not amongst the most profitable firms when it chooses a price that is higher than $p^{n}$ while still competing for the marginal consumers with its neighbours.

On the other hand, when the experimenting firm does not compete for the marginal consumer with its closest neighbours, the difference in profit between the experimenting firm and its neighbour equals

$$
\left(p^{\prime}-c\right) 2 \frac{\beta-p^{\prime}}{\tau}-(p-c)\left(\frac{\beta-p}{\tau}+\frac{1}{2 n}\right)
$$

This expression is negative when $p^{\prime}=2 \beta-p-\frac{\tau}{n}$, and hence, also negative for all $p^{\prime}>2 \beta-p-\frac{\tau}{n}$. Thus, experimenting with $p^{\prime}>p^{n}$ is not successful.

Step 2. Suppose a firm experiments with $p^{\prime}<c+\frac{2 \tau}{3 n}$, implying that all firms compete for the marginal consumer. The demand faced by the experimenting firm equals $\frac{p-p^{\prime}+\frac{\tau}{n}}{\tau}$. The restriction $\tau \geq \frac{2}{3} n(\beta-c)$ implies that an experimenting firm never attracts consumers from a firm that is not closest to it, even when experimenting with marginal cost pricing. As the non-experimenting firms that are not closest to the experimenting firm are not affected, they continue to receive profit $(p-c) \frac{1}{n}$. The closet neighbouring firms of the experimenting firm receive a lower profit as consumers get stolen due to the lower price experimentation. The difference in profit between the experimenting firm over its non-neighbouring firms equals

$$
\left(p^{\prime}-c\right)\left(\frac{p-p^{\prime}+\frac{\tau}{n}}{\tau}\right)-(p-c)\left(\frac{1}{n}\right)=\left(p^{\prime}-p\right)\left(c+\frac{\tau}{n}-p^{\prime}\right) .
$$

The first term in this last expression is negative by assumption. The second term is always positive because $p^{\prime}<c+\frac{2 \tau}{3 n}$. So, an experimentation with $p^{\prime}<c+\frac{2 \tau}{3 n}$ will not induce further imitation of this price. $^{21}$

Part (iii). We have seen that the transition from one monomorphic state in $\Omega_{1}$ to another state in $\Omega_{1}$ is not possible with one experimentation (recall Footnotes 20 and 21 in Part (ii)). Now we show that it is possible with two experimentations.

First, the transition from one monomorphic state in $\Omega_{1}$ to another with a higher price. Suppose that two neighbouring firms experiment with $p^{\prime}>p$ when all other firms choose $p$, with both $p$ and $p^{\prime}$ being in the support of $\Omega_{1}$. As $p^{\prime}$ and $p$ are both less than or equal to $\beta-\frac{\tau}{2 n}$, all neigbouring firms always compete for a marginal consumer. Further, when $p^{\prime}>p$, the most profitable non-experimenting firm is the closest neighbouring firm of the experimenting firm - the experimentation with a higher price results in the latter facing a higher demand than the other non-experimenting firms. The difference in profit between an

firms choose price $p$ in support of $O m e g a_{1}$ and a firm experiments with a higher price $p^{\prime}$ in support of $\Omega_{1}$, the experimenting firm will always compete for the marginal consumer with its direct neighbours. Then, for the same reason as above, the experimenting firm is not the most profitable firm.

${ }^{21}$ Remark: Two comments are in order here. Firstly, this part applies directly to Statements (d) and (e). Secondly, the proof also makes the point that it is not possible to transit from one state in $\Omega_{1}$ with price $p$ to another state in $\Omega_{1}$ with price $p^{\prime}<p$ for the exact same reason. 
experimenting firm over the most successful non-experimenting firm equals

$$
\left(p^{\prime}-c\right)\left(\frac{1}{2 n}+\frac{p-p^{\prime}+\frac{\tau}{n}}{2 \tau}\right)-(p-c)\left(\frac{1}{2 n}+\frac{p^{\prime}-p+\frac{\tau}{n}}{2 \tau}\right)=\frac{1}{2 \tau}\left(p-p^{\prime}\right)\left(p^{\prime}+p-2 c-2 \frac{\tau}{n}\right)
$$

The first term $\left(p-p^{\prime}\right)$ is negative by assumption. The second term is negative since $p$ and $p^{\prime}$ are both at most $\beta-\frac{\tau}{2 n}$, and $\beta-\frac{\tau}{2 n}$ in turn is at most equal to $c+\frac{\tau}{n}$ (due to $\tau>\frac{2}{3} n(\beta-c$ ). Hence, the experimenting firms are most profitable and their experimentation is imitated, showing the transition from one monomorphic state in $\Omega_{1}$ to another with a higher price with two experimentations. ${ }^{22}$

For the transition to a monomorphic state in $\Omega_{1}$ with lower price, we focus on the transition from the state where all firms price according to $p^{n}$ to the state where all firms price according to $c+\frac{2 \tau}{3 n}$ (so, a transition from the highest price in $\Omega_{1}$ to the lowest price in $\Omega_{1}$ ). Let two neighbouring firms experiment with $p^{\prime}=c+\frac{2 \tau}{3 n}$ and $p^{\prime \prime}=2 \beta-p^{\prime}-\frac{\tau}{n}$, and let us call the former the primary experimenting firm and the latter the secondary experimenting firm. The condition $p^{\prime \prime}=2 \beta-p^{\prime}-\frac{\tau}{n}$ implies $p^{\prime \prime}>2 \beta-p^{n}-\frac{\tau}{n}$. So, the secondary experimenting firm does not compete with the neighbouring non-experimenting firm for the marginal consumer. Furthermore, substituting $p^{n}=\beta-\frac{\tau}{2 n}$ in $p^{\prime \prime}>2 \beta-p^{n}-\frac{\tau}{n}$ implies $p^{\prime \prime}>p^{n}$; thus we have a situation where the primary (secondary) experimenting firm experiments with a price that is lower (higher) than the Nash equilibrium price. By Remark 5, we only need to compare the profit of the primary experimenting firm to the most successful non-experimenting firm (which is the closest neighbour of the secondary experimenting firm). The difference between these two profits equals

$$
\left(p^{\prime}-c\right)\left(\frac{2 \beta-p^{\prime}-\frac{\tau}{n}-p^{\prime}+\frac{\tau}{n}}{2 \tau}+\frac{p-p^{\prime}+\frac{\tau}{n}}{2 \tau}\right)-(p-c)\left(\frac{\beta-p}{\tau}+\frac{1}{2 n}\right)=0 .
$$

As the primary experimenting firm is also most profitable, it is imitated by other firms (with positive probability), leading to the state where all firms price according to $c+\frac{2 \tau}{3 n}$.

This shows that it is possible to transit from one monomorphic state in $\Omega_{1}$ to another state in $\Omega_{1}$ with two experimentations. Hence, all states in $\Omega_{1}$ have the same resistance of transition from other states, and all states in $\Omega_{1}$ belong to the stochastically stable set.

Statement (d): $\tau \in\left(\frac{1}{2} n(\beta-c), \frac{2}{3} n(\beta-c)\right)$.

First, we note that it takes a single-firm experimentation to move into the absorbing set $\Omega_{2}$, defined by the monomorphic states where firms set the same price $p \in\left[c+\frac{2 \tau}{3 n}\right.$, $\left.p^{c}\right]$ with $p^{c}=c+\frac{\tau}{n}-$ from any other absorbing state (recall Footnote 19). In Part (ii), we show that it requires more than a single-firm experimentation to transit out of $\Omega_{2}$; so, the stochastically stable set is contained in $\Omega_{2}$. In Part (iii), we show that it is not possible to transit from one

\footnotetext{
${ }^{22}$ This part shows the transition to any monomorphic state with a higher price, as long as the higher price is less than $c+\frac{\tau}{n}$. This fact will be used in the proof of Statements (d) and (e) to establish a similar claim.
} 
state in $\Omega_{2}$ to another with one experimentation. In Part (iv), we show that the transition from one state in $\Omega_{2}$ to another with a higher price is possible with two experimentations. In Part (v), we show that it is not possible to transit from a state in $\Omega_{2}$ to another state in $\Omega_{2}$ with a price lower than $\frac{2 \beta+c-\frac{\tau}{n}}{3}$ with two experimentations. This proves that all states in $\Omega_{2}$ with prices in the interval $\left[\frac{2 \beta+c-\frac{\tau}{n}}{3}, p^{c}\right]$ belong to the stochastically stable set. ${ }^{23}$

Part (ii). First, suppose we are in an absorbing state where all firm choose the same price $p \in\left[c+\frac{2 \tau}{3 n}, p^{c}\right]$ with $p^{c}=c+\frac{\tau}{n}$.

Step 1. Assume that a firm experiments with price $p^{\prime}>p^{c}$ that results in competition for the marginal consumers with its neighbours. ${ }^{24}$ As $p^{\prime}>p^{c}$, the closest neighbouring firms of the experimenting firm are the most profitable non-experimenting firms. The difference in profit between the experimenting firm and the most profitable non-experimenting firm equals

$$
\left(p^{\prime}-c\right)\left(\frac{p-p^{\prime}+\frac{\tau}{n}}{\tau}\right)-(p-c)\left(\frac{p^{\prime}-p+\frac{\tau}{n}}{2 \tau}+\frac{1}{2 n}\right)=\frac{1}{2 \tau}\left(p-p^{\prime}\right)\left(2 p^{\prime}+p-3 c-2 \frac{\tau}{n}\right) .
$$

The first term in the latter expression is negative by assumption. The second term is always positive, as it attains its lowest value when $p=c+\frac{2 \tau}{3 n}$ and $p^{\prime}=p^{c}=c+\frac{\tau}{n}$, where it is equal to $\frac{\tau}{6 n}>0$, and so is also positive for all other feasible values of $p, p^{\prime}$. Thus, the experimentation is not successful. ${ }^{25}$

Step 2. We now focus on the situation where the experimentation $p^{\prime}>p^{c}$ leads to the experimenting firm obtaining a locally segregated market. ${ }^{26}$ The difference in profit between the experimenting firm and its closest neighbouring firm equals

$$
\left(p^{\prime}-c\right) 2 \frac{\beta-p^{\prime}}{\tau}-(p-c)\left(\frac{1}{2 n}+\frac{\beta-p}{\tau}\right) .
$$

Subject to the constraint $p^{\prime} \geq 2 \beta-p-\frac{\tau}{n}$, the profit difference is largest at $p^{\prime}=2 \beta-p-\frac{\tau}{n}$ when the profit difference equals

$$
-\frac{1}{\tau}\left(p-\beta+\frac{\tau}{2 n}\right)\left(3 c+p+4 \frac{\tau}{n}-4 \beta\right) .
$$

\footnotetext{
${ }^{23}$ Remark: Parts (ii) $-(\mathrm{v})$ are valid for $\tau<\frac{2}{3} n(\beta-c)$, and thus, directly relevant for the proof of Statement (e) as well.

${ }^{24}$ An experimentation with $p^{\prime}<p$ is not successful - recall Footnote 21 - and so we do not consider this here.

${ }^{25}$ Remark: While this part of the proof explicitly considers the possibility of transition from a state in $\Omega_{2}$ to a state outside it with a higher price, it can also be used to see that it is not possible to transit from a state in $\Omega_{2}$ where firms choose the price $p \in\left[c+\frac{2 \tau}{3 n}, p^{c}\right]$ to another state in $\Omega_{2}$ where all firms choose $p^{\prime} \in\left[c+\frac{2 \tau}{3 n}, p^{c}\right]$ with $p^{\prime}>p$. That is, if in the initial state, all firms choose $p$ in support of $\Omega_{2}$ and now a firm experiments with $p^{\prime}$ in support of $\Omega_{2}$, then all firms compete for the marginal consumer - this is because the highest price in $\Omega_{2}$ is lower than $\beta-\frac{\tau}{2 n}$. So, the expressions derived in the main text can be used for the profit comparison. Then, it can be seen that $\left(p-p^{\prime}\right)$ is negative by assumption as before; $\left(2 p^{\prime}+p-3 c-2 \frac{\tau}{n}\right)$ is positive as before, where the latter holds because $\left(2 p^{\prime}+p-3 c-2 \frac{\tau}{n}\right)$ attains a value of zero when $p=p^{\prime}=c+\frac{2 \tau}{3 n}$, and so it is positive for all $p$ and $p^{\prime}$ in $\left[c+\frac{2 \tau}{3 n}, p^{c}\right]$ with $p<p^{\prime}$.

${ }^{26}$ A necessary condition for this is $\beta-p-\frac{\tau}{n}<0$ as otherwise the consumer situated at the location of the closest neighbouring firm would receive positive utility from the experimenting firm, precluding the possibility of segregated markets. Given the upper bound on $\tau$, this necessary condition is least strict when $p=c+\frac{\tau}{n}$; in this case, $\beta-p-\frac{\tau}{n}<0$ gives $\tau>\frac{1}{2} n(\beta-c)$ - for lower values of prices in $\Omega_{2}$, the constraint on $\tau$ is even more strict (given the upper bound on it). In addition, $p^{\prime}$ has to satisfy $p^{\prime} \geq 2 \beta-p^{c}-\frac{\tau}{n}=2 \beta-c-\frac{2 \tau}{n}$.
} 
The restrictions $\tau<\frac{2}{3} n(\beta-c)$ and $p \in\left[c+\frac{2 \tau}{3 n}, c+\frac{\tau}{n}\right]$ imply $p<p^{n}=\beta-\frac{\tau}{2 n}$. From these conditions it is easily derived that the first term as well as the second term are negative. So, single firm experimentations are not successful.

Part (iii). Here, we establish that it is not possible to transit from a state in $\Omega_{2}$ to another state in $\Omega_{2}$ with one experimentation. When all firms price at $p \in\left[c+\frac{2 \tau}{3 n}, p^{c}\right]$ and a firm experiments with $p^{\prime} \in\left[c+\frac{2 \tau}{3 n}, p^{c}\right]$, all firms compete for the marginal consumer. We have commented in Footnotes 19, 20 and 25 that experimentations both with $p^{\prime}<p$ and with $p^{\prime}>p$ are not successful. Thus, a single firm experimentation does not cause a transition from any state in $\Omega_{2}$ to another state in $\Omega_{2}$.

Part (iv). Follows directly from part(iii) in statement (c) (recall Footnote 22).

Part (v). Two types of transitions are possible when two firms experiment from the state where all firms choose $p^{c}$. First, in (1), we consider transitions via higher prices. We show that while it is possible to transit to monomorphic states with a price in the interval $\left(p^{c}, \frac{2 \beta+c}{3}\right]$, it is not possible to transit from any of these states to another monomorphic state where the price is either higher than $\frac{2 \beta+c}{3}$ or lower than $p^{c}$. That is, the transition to any other state with price either strictly higher than $\frac{2 \beta+c}{3}$ or strictly lower than $p^{c}$ from monomorphic states where the price is in the interval $\left(p^{c}, \frac{2 \beta+c}{3}\right]$ requires at least two experimentations, while such a transition to the state where all firms choose $p^{c}$ has been shown to be possible with one experimentation.

Second, in (2), we consider transitions via lower prices. We show that while it is possible to transit to monomorphic states with a price in the interval $\left[\frac{2 \beta+c-\frac{\tau}{n}}{3}, p^{c}\right)$, where $\frac{2 \beta+c-\frac{\tau}{n}}{3}>c+\frac{2 \tau}{3 n}$ (under the current restriction on $\tau$ ), again, from any of these states, it is not possible to transit to monomorphic states where the price is in the interval $\left[c+\frac{2 \tau}{3 n}, \frac{2 \beta+c-\frac{\tau}{n}}{3}\right)$ whereas it is possible to transit to states with price in $\left[\frac{2 \beta+c-\frac{\tau}{n}}{3}, p^{c}\right]$ with two experimentations.

On the assumption that no other type of transition is possible when two firms experiment from the state where all firms choose $p^{c},(1)$ and (2) enable the conclusion that the monomorphic states with price in the interval $\left[c+\frac{2 \tau}{3 n}, \frac{2 \beta+c-\frac{\tau}{n}}{3}\right)$ need more experimentations to transit into relative to monomorphic states in $\left[\frac{2 \beta+c-\frac{\tau}{n}}{3}, p^{c}\right]$. Finally, in (3), we show that no other type of transition is possible when two firms experiment from the state where all firms choose $p^{c}$. This establishes that the stochastically stable set is described by monomorphic states where firms price choose a price in the interval $\left[\frac{2 \beta+c-\frac{\tau}{n}}{3}, p^{c}\right]$.

(1) Suppose two neighbouring firms experiment with $p^{\prime}$ and $p^{\prime \prime}=2 \beta-p^{\prime}-\frac{\tau}{n}$, such that both these prices are higher than $p^{c}$. Let the firm with price $p^{\prime}\left(p^{\prime \prime}\right)$ be called the primary (secondary) experimenter. Also, let $p^{\prime}<p^{\prime \prime}$ so that the non-experimenting neighbour of the secondary experimenting firm is the most profitable non-experimenting firm. Further, because $p^{\prime \prime}=2 \beta-p^{\prime}-\frac{\tau}{n}$ and $p^{c}<p^{\prime}$, we have $p^{\prime \prime}<2 \beta-p^{c}-\frac{\tau}{n}$, implying that the secondary experimenting firm and its non-experimenting neighbour compete for the marginal 
consumer. Due to reasons stated earlier, the secondary experimenter can never be more profitable than the most profitable non-experimenting firm. The difference in profit between the primary experimenter over the non-experimenting neighbour of the secondary experimenting firm equals

$$
\left(p^{\prime}-c\right)\left(\frac{p^{c}-p^{\prime}+\frac{\tau}{n}}{2 \tau}+\frac{\beta-p^{\prime}}{\tau}\right)-\left(p^{c}-c\right)\left(\frac{1}{2 n}+\frac{p^{\prime \prime}-p^{c}+\frac{\tau}{n}}{2 \tau}\right)=\frac{1}{2 \tau}\left(p^{\prime}-p^{c}\right)\left(2 \beta+c-3 p^{\prime}\right) .
$$

It follows that the primary experimenting firm is at least as profitable as any other firm when $p^{\prime} \in\left(p^{c}, \frac{2 \beta+c}{3}\right] .^{27}$

Since $p^{\prime} \leq \frac{2 \beta+c}{3}<\beta-\frac{\tau}{2 n}$ due to the restriction on transportation cost, all firms compete for the marginal consumer and serve a market of size $\frac{1}{n}$ each in the state where all firms $p^{\prime}$. We will now show that a single firm experimentation is not successful in making it possible to transit from this state to a monomorphic state where the price is lower than $p^{c}$ or higher than $\frac{2 \beta+c}{3}$. There are three types of single firm experimentations possible and we consider them one by one.

Firstly, suppose that a firm experiments with $p^{\prime \prime \prime}$ such that $p^{\prime \prime \prime}<p^{c}<p^{\prime}$. As all firms still compete for the marginal consumer, the difference in profit between the experimenting firm and the most profitable non-experimenting firm equals

$$
\left(p^{\prime \prime \prime}-c\right)\left(\frac{p^{\prime}-p^{\prime \prime \prime}+\frac{\tau}{n}}{\tau}\right)-\left(p^{\prime}-c\right)\left(\frac{1}{n}\right)=\frac{1}{\tau}\left(p^{\prime \prime \prime}-p^{\prime}\right)\left(c+\frac{\tau}{n}-p^{\prime \prime \prime}\right)<0 .
$$

Hence, the experimenting firm is not the most profitable.

Secondly, suppose the experimentation is with a price $p^{\prime \prime \prime}>\frac{2 \beta+c}{3}$, but such that it competes for the marginal consumer. Then, the difference in profit between the experimenting firm and the most profitable non-experimenting firm equals

$$
\left(p^{\prime \prime \prime}-c\right)\left(\frac{p^{\prime}-p^{\prime \prime \prime}+\frac{\tau}{n}}{\tau}\right)-\left(p^{\prime}-c\right)\left(\frac{p^{\prime \prime \prime}-p^{\prime}+\frac{\tau}{n}}{\tau}\right)=\frac{1}{\tau}\left(p^{\prime}-p^{\prime \prime \prime}\right)\left(p^{\prime}+p^{\prime \prime \prime}-\frac{\tau}{n}-2 c\right)<0 .
$$

Here as well, the experimenting firm is not the most profitable.

Finally, suppose the experimentation is with a price $p^{\prime \prime \prime}>\frac{2 \beta+c}{3}$, but such that it does not compete for the marginal consumer. This happens when $p^{\prime \prime \prime} \geq 2 \beta-p^{\prime}-\frac{\tau}{n}$, and it can be verified that under the current setting, this implies $p^{\prime \prime \prime}>\beta-\frac{\tau}{2 n}$. Then, the difference in profit between the experimenting firm and the most profitable non-experimenting firm equals

$$
\left(p^{\prime \prime \prime}-c\right)\left(2 \frac{\beta-p^{\prime \prime \prime}}{\tau}\right)-\left(p^{\prime}-c\right)\left(\frac{1}{2 n}+\frac{\beta-p^{\prime}}{\tau}\right) .
$$

\footnotetext{
${ }^{27}$ Remark: This is applicable only when the secondary experimenting firm itself faces positive demand, and yet gives the primary experimenter a segregated market - for this to happen, it must be that $\beta-p^{c}-\frac{\tau}{n}<0$, or $\tau \geq \frac{1}{2} n(\beta-c)$. If, on the contrary, $\beta-p^{c}-\frac{\tau}{n}>0$ were to hold, the consumer located at the primary experimenting firm would obtain a positive utility on purchasing from the secondary experimenting firm, precluding the possibility of a segregated market between the two experimenting firms. Consequently, the type of experimentation referred to in the text is not possible if $\tau<\frac{1}{2} n(\beta-c)$.
} 
The experimenting firm's profit $\left(p^{\prime \prime \prime}-c\right)\left(2 \frac{\beta-p^{\prime \prime \prime}}{\tau}\right)$ is decreasing in $p^{\prime \prime \prime}$ whenever $p^{\prime \prime \prime}>\frac{\beta+c}{2}$. As $\beta-\frac{\tau}{2 n}>\frac{\beta+c}{2}$ and $p^{\prime \prime \prime}>\beta-\frac{\tau}{2 n}$, the experimenting firm's profit is decreasing in $p^{\prime \prime \prime}$. So, the above expression attains its maximum when $p^{\prime \prime \prime}=2 \beta-p^{\prime}-\frac{\tau}{n}$, where it equals

$$
\frac{2}{\tau}\left(\beta-c-\frac{\tau}{n}\right)\left(2 p^{\prime}+\frac{\tau}{n}-2 \beta\right)
$$

The restrictions $\tau<\frac{2}{3} n(\beta-c)$ and $p^{\prime} \in\left(c+\frac{\tau}{n}, \frac{2 \beta+c}{3}\right]$ imply $p^{\prime}<\beta-\frac{\tau}{2 n}$. From these conditions it is easily derived that the first term as well as the second term are negative, and so, the experimenting firm is not the most profitable. So, a single firm experimentation is not successful in making it possible to transit from monomorphic states where the price lies in the interval $\left(c+\frac{\tau}{n}, \frac{2 \beta+c}{3}\right]$ to a monomorphic state where the price is lower than $p^{c}$ or higher than $\frac{2 \beta+c}{3}$.

(2) Suppose the primary experimenting firm experiments with price $p^{\prime}$ while the secondary experimenting firm experiments with a price $p^{\prime \prime}$ such that the latter faces zero demand. This makes the non-experimenting neighbour of the secondary experimenting firm the most profitable amongst the non-experimenting firms. Under this situation, there are two cases: one where the primary experimenting firm competes with the non-experimenting neighbour of the secondary experimenting firm, and one where it does not. We will later show that if they compete for the marginal consumer under this type of experimentation, then the experimentation is not successful. First, we focus on the case where they do not compete. The difference in profit between the experimenting firm and the most profitable non-experimenting firm equals

$$
\left(p^{\prime}-c\right)\left(\frac{p^{c}-p^{\prime}+\frac{\tau}{n}}{2 \tau}+\frac{\beta-p^{\prime}}{\tau}\right)-\left(p^{c}-c\right)\left(\frac{1}{2 n}+\frac{\beta-p^{c}}{\tau}\right)=\frac{1}{2 \tau}\left(p^{\prime}-p^{c}\right)\left(2 \beta+c-\frac{\tau}{n}-3 p^{\prime}\right) .
$$

Suppose $\left(p^{\prime}-p^{c}\right)>0$. Then because $\left(2 \beta+c-\frac{\tau}{n}-3 p^{\prime}\right)<0$ for $p^{\prime}=p^{c}$, and because it is decreasing in $p^{\prime}$, it is negative for all $p^{\prime}>p^{c}$. Hence, the experimenting firm is not successful. Now suppose that $\left(p^{\prime}-p^{c}\right)<0$. Then, the primary experimenting firm is at least as profitable as any other firm if $p^{\prime} \geq \frac{2 \beta+c-\frac{\tau}{n}}{3}$. It can be verified that $\frac{2 \beta+c-\frac{\tau}{n}}{3} \leq c+\frac{\tau}{n}$ when $\tau \geq \frac{1}{2} n(\beta-c)$, and $\frac{2 \beta+c-\frac{\tau}{n}}{3} \geq c+\frac{2 \tau}{3 n}$ when $\tau \geq \frac{2}{3} n(\beta-c)$, and that $\frac{2 \beta+c-\frac{\tau}{n}}{3}$ is decreasing in the transportation cost. This results in all firms imitating the price $p^{\prime} \in\left[\frac{2 \beta+c-\frac{\tau}{n}}{3}, p^{c}\right)$.

We will now show that it is not possible to transit from such a state to a monomorphic state with price in the interval $\left[c+\frac{2 \tau}{3 n}, \frac{2 \beta+c-\frac{\tau}{n}}{3}\right)$ when two firms experiment. ${ }^{28}$ As argued in Remark 3, we assume the experimenters to be neighbouring firms. Let the price in the initial state be $p \in\left[\frac{2 \beta+c-\frac{\tau}{n}}{3}, p^{c}\right]$, and let two neighbouring firms experiment with $p^{\prime}$ (the primary

\footnotetext{
${ }^{28}$ It has already been shown in (iii) and (iv) above that it is not possible to exit such states with a single firm experimentation, and that it is possible to transit from such states to the state with Nash equilibrium price with two experimentations.
} 
experimenting firm) and $p^{\prime \prime}$ (the secondary experimenting firm), with $p^{\prime \prime} \geq p^{\prime} .^{29,30}$

Step 1. Let $p^{\prime}$ and $p^{\prime \prime}$ be at most equal to $p$, i.e. both the experimenting firms experiment with a lower price. Then, using similar reasoning used to argue for Remark 4, we conclude that there exists a non-experimenting firm that is more profitable than both the non-experimenting firms.

Step 2. Let us now assume $p^{\prime \prime}>p$ and $p^{\prime \prime}>p^{\prime}$. Then, the non-experimenting neighbour of the secondary experimenting firm is the most profitable non-experimenting firm: $p^{\prime \prime}>p$ allows the former to attract more consumers than other non-experimenting firms. The difference in profit between the primary experimenting firm and the most profitable non-experimenting firm equals

$$
\left(p^{\prime}-c\right)\left(\frac{p-p^{\prime}+\frac{\tau}{n}}{2 \tau}+\frac{p^{\prime \prime}-p^{\prime}+\frac{\tau}{n}}{2 \tau}\right)-(p-c)\left(\frac{1}{2 n}+\frac{p^{\prime \prime}-p+\frac{\tau}{n}}{2 \tau}\right) .
$$

The derivative of this expression with respect to $p^{\prime \prime}$ is $\left(p^{\prime}-p\right)$.

First, suppose $p^{\prime}<p$, so that the relative profit is decreasing in $p^{\prime \prime}$. When $p^{\prime \prime}=p$ (i.e. the situation is equivalent to a single firm experimentation), we know that the primary experimenting firm is not the most profitable. So, the expression is negative for all $p^{\prime \prime}>p$.

Second, when $p^{\prime}>p$, the expression is increasing in $p^{\prime \prime}$. So, the relative profit of the primary experimenter is maximised when $p^{\prime \prime}$ takes the highest feasible value such that the profit function is still valid. This corresponds to the secondary experimenting firm choosing a price of $\beta$, at which it receives zero demand, and we analyse such cases in the next step. ${ }^{31}$ Step 3. Let $p^{\prime \prime}>p$ be such that the secondary experimenting firm does not face any demand. Then there are two situations, depending on whether there is competition for the marginal consumer between the primary experimenting firm and the most profitable non-experimenting firm (identified earlier as the neighbour of the secondary experimenting firm).

First, suppose they compete for the marginal consumer and this happens when $p^{\prime} \leq$ $2 \beta-p-2 \frac{\tau}{n}$. Then the difference in profit between the primary experimenting firm and the most profitable non-experimenting firm equals

$$
\left(p^{\prime}-c\right)\left(\frac{p-p^{\prime}+\frac{2 \tau}{n}}{2 \tau}+\frac{p-p^{\prime}+\frac{\tau}{n}}{2 \tau}\right)-(p-c)\left(\frac{1}{2 n}+\frac{p^{\prime}-p+\frac{2 \tau}{n}}{2 \tau}\right)=\frac{1}{2 \tau}\left(p-p^{\prime}\right)\left(2 p^{\prime}+p-3 \frac{\tau}{n}-3 c\right) .
$$

If $\left(p-p^{\prime}\right)>0$, then $\left(2 p^{\prime}+p-3 \frac{\tau}{n}-3 c\right)<0$ as $p \leq c+\frac{\tau}{n}$, leading to the experimenting firm not being the most profitable. Suppose, on the other hand, that $\left(p-p^{\prime}\right)<0$. The condition

\footnotetext{
${ }^{29}$ Note that we include $p^{c}$ in the set of prices of the initial monomorphic states, and so the transition impossibilities that follow are relevant for the monomorphic state with price $p^{c}$ as well, a fact that we will use in (3) and Statement (e) to follow.

${ }^{30}$ Also note that Step 1 and Step 2 to follow is directly applicable not only for $p \in\left[\frac{2 \beta+c-\frac{\tau}{n}}{3}, p^{c}\right]$ but also for $p \in\left[\frac{2 \beta+c-\frac{\tau}{n}}{3}, \frac{2 \beta+c}{3}\right]$. We will make use of this in the proof of Proposition 5 .

${ }^{31}$ By Footnote 27, the secondary experimenting firm cannot experiment with a price such that it obtains positive demand while giving the primary experimenting firm a segregated market when $\tau<\frac{1}{2} n(\beta-c)$. So, if the primary experimenter does not compete with the secondary experimenting firm, it must imply that the secondary experimenter faces zero demand.
} 
$p^{\prime} \leq 2 \beta-p-2 \frac{\tau}{n}$ has to be fulfilled at the same time. It can then be seen that if $p \geq \beta-\frac{\tau}{n}$, then $\left(p-p^{\prime}\right)<0$ and $p^{\prime} \leq 2 \beta-p-2 \frac{\tau}{n}$ cannot hold together; further, the price $\frac{2 \beta+c-\frac{\tau}{n}}{3}$ is greater than $\beta-\frac{\tau}{n}$ whenever $\tau>\frac{1}{2} n(\beta-c)$. This implies that all prices in the interval $\left[\frac{2 \beta+c-\frac{\tau}{n}}{3}, p^{c}\right]$ are greater than $\beta-\frac{\tau}{n}$, implying that the required conditions cannot be satisfied simultaneously. So, this type of experimentation is not successful. ${ }^{32}$

Second, suppose the primary experimenting firm and the most profitable non-experimenting firm do not compete for the marginal consumer, which happens when $p^{\prime}>2 \beta-p-2 \frac{\tau}{n}$. The difference in profit between the experimenting firm and the most profitable non-experimenting firm equals

$$
\left(p^{\prime}-c\right)\left(\frac{p-p^{\prime}+\frac{\tau}{n}}{2 \tau}+\frac{\beta-p^{\prime}}{\tau}\right)-(p-c)\left(\frac{1}{2 n}+\frac{\beta-p}{\tau}\right)=\frac{1}{2 \tau}\left(p^{\prime}-p\right)\left(2 \beta+3 c+\frac{\tau}{n}-3 p^{\prime}-2 p\right) .
$$

First, if $\left(p^{\prime}-p\right)<0$, the relative profit expression will be positive if $\frac{2 \beta+3 c+\frac{\tau}{n}-2 p}{3} \leq p^{\prime}$. Since $p \in\left[\frac{2 \beta+c-\frac{\tau}{n}}{3}, p^{c}\right]$, the lowest value of $p^{\prime}$ such that the relative profit is positive is $\frac{2 \beta+3 c+\frac{\tau}{n}-2 p}{3}$ with $p=p^{c}=c+\frac{\tau}{n}$, where it equals $\frac{2 \beta+c-\frac{\tau}{n}}{3}$. As $\frac{2 \beta+3 c+\frac{\tau}{n}-2 p}{3}$ is decreasing in $p$, the lowest experimenting price such that the experimentation is successful must be greater than $\frac{2 \beta+c-\frac{\tau}{n}}{3}$ for other (lower) prices $p$ in $\left[\frac{2 \beta+c-\frac{\tau}{n}}{3}, p^{c}\right]$. Thus, this experimentation does not cause an exit from the monomorphic states where price lies in $\left[\frac{2 \beta+c-\frac{\tau}{n}}{3}, p^{c}\right]$.

On the other hand, suppose $\left(p^{\prime}-p\right)>0$. The above expression will be positive if $\frac{2 \beta+3 c+\frac{\tau}{n}-2 p}{3} \geq p^{\prime}$. Now as $p \in\left[\frac{2 \beta+c-\frac{\tau}{n}}{3}, p^{c}\right]$, the highest possible $p^{\prime}$ such that the experimentation is successful is $\frac{2 \beta+3 c+\frac{\tau}{n}-2 p}{3}$ with $p=\frac{2 \beta+c-\frac{\tau}{n}}{3}$ - for other (higher) values of $p$, the highest possible $p^{\prime}$ such that the experimentation is successful is lower. It can now be checked that $p^{\prime}=\frac{2 \beta+3 c+\frac{\tau}{n}-2 p}{3}$ with $p=\frac{2 \beta+c-\frac{\tau}{n}}{3}$ is lower than $\frac{2 \beta+c}{3}$ whenever $\tau<\frac{5}{4} n(\beta-c)$ (and thus in this case as well). So, a successful experimentation will at most lead to monomorphic states with price in the interval $\left(p^{c}, \frac{2 \beta+c}{3}\right] .{ }^{33}$ We have shown that from this resulting monomorphic state, it is not possible to transit to monomorphic states with price $\left[c+\frac{2 \tau}{3 n}, \frac{2 \beta+c-\frac{\tau}{n}}{3}\right)$ with a single experimentation. This shows that states in $\Omega_{2}$ with price in $\left[c+\frac{2 \tau}{3 n}, \frac{2 \beta+c-\frac{\tau}{n}}{3}\right)$ need more experimentations to transit into them, and so these are not supported in the stochastically stable set.

(3) Finally, note (by recalling Footnote 29) that the preceding part has shown that from the state where all firms choose the price $p^{c}$ there is no other type of two-firm experimentation that is successful apart from the two types described above.

This proves that only monomorphic states with price in the interval $\left[\frac{2 \beta+c-\frac{\tau}{n}}{3}, p^{c}\right)$ are supported in the long-run.

\footnotetext{
${ }^{32}$ Note that this also shows that it is not possible to transit to a state with a higher price if the price in the initial state is in the interval $\left[p^{c}, \frac{2 \beta+c}{3}\right]$. We will make use of this in the proof of Proposition 5.

${ }^{33}$ Note that this also shows that it is not possible to transit to a state with a price higher than $\frac{2 \beta+c}{3}$ if the price in the initial state is in the interval $\left[p^{c}, \frac{2 \beta+c}{3}\right]$. We will make use of this in the proof of Proposition 5
} 
Statement (e): $\tau<\frac{1}{2} n(\beta-c)$.

In proving the previous statements we have shown that:

(i) the stochastically stable states are contained in set $\Omega_{2}$ (defined in Statement (d)) as transitions into $\Omega_{2}$ requires one experimentation while a transit out of $\Omega_{2}$ needs two experimentations (Footnote 19),

(ii) it is not possible to transit from a state in $\Omega_{2}$ to another state in $\Omega_{2}$ with one experimentation (Footnotes 23 and 25),

(iii) the transition from a state $\Omega_{2}$ to another state in $\Omega_{2}$ with a higher price is possible with two experimentations, implying in combination with (i) that the transition to the state where all firms price at $p^{c}=c+\frac{\tau}{n}$ needs at most two experimentations (Footnote 22), and

(iv) it is not possible to transit from the state where firms price at $p^{c}=c+\frac{\tau}{n}$ to other states with two experimentations. ${ }^{34}$

These properties together establish that the state where all firms price at $p^{c}=c+\frac{\tau}{n}$ is the unique stochastically stable state.

\section{Proof of Lemma 1}

We will show that the absorbing set is contained purely of monomorphic states. Suppose that we are in a state where all firms use a different price. After profits are realised, the most profitable firm is imitated by its $k$ closest neighbours on each side. Given the restriction on the minimum number of other firms each firm observes, there are at most four different prices in the firm population after the first round of imitation. To see this, we assume that observability is at its lowest, i.e. $k=\max \left\{2, \frac{n-4}{4}\right\}$. Then, the most profitable firm, which prices at, say $p_{1}$, is imitated by at at least $\frac{n}{2}-2$ other firms. ${ }^{35}$ Thus $p_{1}$ is used (after the first round of imitation) by $\frac{n}{2}-1$ firms. The most profitable of the remaining firms, which prices at, say $p_{2}$, is imitated by at least $\frac{n-4}{4}$ other firms. So, $p_{2}$ is used by $\frac{n}{4}$ firms in all. Out of the firms that remain after this, the most profitable one, with price of, say $p_{3}$, is similarly imitated by $\frac{n-4}{4}$ other firms. So, $p_{3}$ is used by $\frac{n}{4}$ firms in all. Adding the number of firms, $n-1$ firms use at most three prices. Let the remaining firm have a different price $p_{4}$. It follows, after the first round of imitation, at most four different prices are in use. ${ }^{36}$

Let $P_{i}$ be the set of firms using price $p_{i}$, and let $B_{i, j}$ be the set of firms that have the closest neighbour on either side using $p_{i}$ and $p_{j}$. Further, there is only one block of contiguous

\footnotetext{
${ }^{34}$ In part (v) of Statement (d), a transition from the state where all firms choose $p^{c}$ to monomorphic states with price in $\left[\frac{2 \beta+c-\frac{\tau}{n}}{3}, p^{c}\right)$ was possible when two firms experiment. But now, under the restriction on $\tau$, $\frac{2 \beta+c-\frac{\tau}{n}}{3}>p^{c}$, so that the said transition is no longer possible when at most two firms experiment. Further, by Footnote 27, the transition to monomorphic states with higher prices is not possible either.

${ }^{35}$ For simplify, we assume $\frac{n-4}{4} \geq 2$, i.e. $k=\frac{n-4}{4}$.

${ }^{36}$ Obviously, the number of different prices in use after the first round of imitation is non-increasing in $k$, and the arguments have been made for the lowest possible value of $k$, the observability parameter.
} 
firms that choose the same price. Now, there are two possibilities:

(1) The firm with price $p_{4}$ observes some other firm to be the most profitable in its observation neighbourhood and imitates it. This results in at most the prices $p_{1}, p_{2}$ and $p_{3}$ being used in the population of firms. Now, assume (wlog) a firm with price $p_{2}$ to be most profitable. Firstly, if this firm is in $P_{2} \backslash\left\{B_{1,2} \cup B_{2,3}\right\}$, then $p_{2}$ is imitated by $2(k-1)$ firms, and since the most profitable firm is in $P_{2} \backslash\left\{B_{1,2} \cup B_{2,3}\right\}$, it continues to be the most profitable. ${ }^{37}$ By iteration of the same reasoning, successive rounds of imitation lead to a monomorphic state where all firms choose $p_{2}$. Secondly, if the most profitable firm (with price $p_{2}$ by assumption) is in $B_{1,2}$, it is imitated by $k$ other firms with price $p_{1} \cdot{ }^{38}$ In fact the firm in $B_{1,2}$ continues to be the most profitable as long as there is a firm with price $p_{1}$. It follows that successive rounds of imitation lead to a state where firms price at $p_{2}$ or $p_{3} \cdot{ }^{39}$ An iteration of the same reasoning from this state results in either $p_{2}$ or $p_{3}$ being imitated, leading to a monomorphic state.

(2) On the other hand, if the firm with price $p_{4}$ is the most profitable firm, then the set of firm using it expands. However, using the same reasoning, it can be reasoned that the set of prices used by the firm population shrinks till a monomorphic state is realized.

\section{Proof of Proposition 5}

Case I: $\tau>\frac{6}{7} n(\beta-c)$.

We first focus on transitions into the Nash equilibrium state. Under complete observability, a single firm experimentation was sufficient to induce this transition. Because of Remark 8 and Remark 9, we only have to consider the transitions from states with a higher price than the Nash equilibrium price $\left(p_{\text {nash }}\right)$, i.e. from states with a price that is higher than $\beta-\frac{\tau}{2 n} .{ }^{40}$ However, when $p>p_{\text {nash }}$, the firms do not compete for the marginal consumer, and so this single firm experimentation is successful (recall Remark 10). So, even now, a single experimentation suffices to transit into the Nash equilibrium, while by Remark 7, it takes more than one single firm experimentation. Thus, the Nash equilibrium state is the stochastically stable state.

\footnotetext{
${ }^{37}$ In fact, all firms in $P_{2} \backslash\left\{B_{1,2} \cup B_{2,3}\right\}$ have the same profit and so all these firms belong to the set of most profitable firms.

${ }^{38}$ If the most profitable firm is in $B_{2,3}$, then the logic is similar and so we do not argue for it explicitly.

${ }^{39}$ If a firm with price $p_{2}$ is more profitable than the firms with price $p_{3}$, then firms with price $p_{3}$ also imitate $p_{2}$ leading to a monomorphic state with price $p_{2}$.

${ }^{40}$ When $\tau>n(\beta-c)$, then the Nash equilibrium price, which is also the monopoly price is higher than $\beta-\frac{\tau}{2 n}$. For $\tau \in\left[\frac{6}{7} n(\beta-c), n(\beta-c)\right]$, the Nash equilibrium price is $\beta-\frac{\tau}{2 n}$.
} 
Case II: $\tau \in\left[\frac{2}{3} n(\beta-c), \frac{6}{7} n(\beta-c)\right)$.

Here, the Nash equilibrium price $p_{\text {nash }}$ equals $\beta-\frac{\tau}{2 n}$, and we will show that the Nash equilibrium state is the stochastically stable state. In the complete observability case, we have shown that from a monomorphic state where the price is higher than the Nash equilibrium price, a single firm experimentation with the Nash equilibrium price brings about a transition to the Nash equilibrium state. By Remark 9 and Remark 10, this continues to hold. On the other hand, we have shown in the complete observability case that if in the initial monomorphic state the price is lower than $c+\frac{2 \tau}{3 n}$, and a firm experiments with the price $c+\frac{2 \tau}{3 n}$, it is most profitable. By Remark 8, this continues to hold. Thus, it is possible to transit into monomorphic states with price in $\left[c+\frac{2 \tau}{3 n}, p_{n a s h}\right]$ with one experimentation, even under incomplete observability. Further, the complete observability case has shown that it is not possible to exit monomorphic states where the price lies in $\left[c+\frac{2 \tau}{3 n}, p_{n a s h}\right]$ with a single experimentation, and by Remark 7, this is true even with incomplete observability. This establishes that for states in the stochastically stable set, the price lies within $\left[c+\frac{2 \tau}{3 n}, p_{n a s h}\right]$. In addition, we know from the proof of the complete observability proposition that if the initial monomorphic state has a price which lies in the interval $\left[c+\frac{2 \tau}{3 n}, p_{n a s h}\right]$, and if two neighbouring firms experiment with a higher price in this interval, then the experimenting firms are the most profitable firms, due to which the higher price in the interval is adopted by imitation by all other firms. By Remark 11, this holds under incomplete observability. So, it takes two experimentations to transit into the Nash equilibrium state.

We now examine transitions from the Nash equilibrium state. It has been shown that a single experimentation is unsuccessful under complete observability, and by Remark 7, it is also unsuccessful under incomplete observability. So, we look into the possibility of exiting the Nash equilibrium state with two experimentations. We argue, as in the complete observability case, that if it is not possible to exit this state with one experimentation, it is not possible to exit it with two non-neighbouring firms experimenting. Hence, we focus on two neighbouring firms experimenting.

First, assume that both the neighbouring firms experiment with the same price $p^{\prime}$. If $p^{\prime}>p_{\text {nash }}=\beta-\frac{\tau}{2 n}$, then the profit of an experimenting firm is lower than that of a nonexperimenting firm that receives a profit of $\pi\left(p_{\text {nash }}, p_{\text {nash }}, p_{\text {nash }}\right)$. This is because the profit function of the experimenting firm, which does not compete for the marginal consumer, is $2(p-$ c) $\frac{\beta-p}{\tau}$, which is decreasing in $p$ if $p \geq \beta-\frac{\tau}{2 n}$. Under our incomplete observability setting, each firm observes a firm obtaining a profit of $\pi\left(p_{\text {nash }}, p_{\text {nash }}, p_{\text {nash }}\right)$, and so the experimentation is not imitated. ${ }^{41}$ On the other hand, if $p^{\prime}<p_{n a s h}=\beta-\frac{\tau}{2 n}$, then the most profitable non-

\footnotetext{
${ }^{41}$ This also implies that a necessary condition for the two firm experimentation to be successful is that at least one firm has to choose a price lower than $p_{\text {nash }}$.
} 
experimenting firm receives $\pi\left(p_{\text {nash }}, p_{\text {nash }}, p_{\text {nash }}\right)$. It may then be seen that the relative profit $\pi\left(p^{\prime}, p^{\prime}, p_{\text {nash }}\right)-\pi\left(p_{\text {nash }}, p_{\text {nash }}, p_{\text {nash }}\right)$ equals

$$
\left(p^{\prime}-c\right)\left(\frac{1}{2 n}+\frac{p-p^{\prime}+\frac{\tau}{n}}{2 \tau}\right)-\left(p_{\text {nash }}-c\right) \frac{1}{n}=\frac{1}{2 \tau}\left(p^{\prime}-p_{\text {nash }}\right)\left(c+2 \frac{\tau}{n}-p^{\prime}\right)<0 .
$$

The negative sign follows from the fact that $p^{\prime}-p_{\text {nash }}<0$ (by assumption) and $c+2 \frac{\tau}{n}-p^{\prime}<0$ is not compatible with $p^{\prime}-p_{\text {nash }}<0$ under the restriction on $\tau .{ }^{42}$ Thus, experimentations when both experimenting firms experiment with the same price are not successful.

Let us now consider two-firm experimentations where the experimenting firms choose different prices. Suppose that such a two-firm experimentation is successful. As argued earlier, the experimenting firm that is most profitable must experiment with a price lower than $p_{\text {nash }}$. After the first wave of imitation, a contiguous block of firms price at $p^{\prime}$, and the firm that obtains the profit $\pi\left(p^{\prime}, p^{\prime}, p\right)$ is the most profitable amongst them (because $\left.p^{\prime}<p_{\text {nash }}\right)$. The remaining firms persist with $p_{\text {nash }}$, and the most profitable amongst them receives a profit $\pi\left(p_{\text {nash }}, p_{\text {nash }}, p_{\text {nash }}\right)$. We have shown $\pi\left(p^{\prime}, p^{\prime}, p_{\text {nash }}\right)<\pi\left(p_{\text {nash }}, p_{\text {nash }}, p_{\text {nash }}\right)$; further, all the firms that choose $p$ and a subset of the firms that choose $p^{\prime}$ observe at least one firm obtaining $\pi(p, p, p)$. This starts a chain of imitation of $p_{\text {nash }}$ till all firms choose it.

We have shown it is not possible to exit the Nash equilibrium state with two experimentations but it is possible to enter it with two experimentations, proving that the Nash equilibrium state is the stochastically stable state.

Case III: $\tau \in\left[\frac{2}{3} n(\beta-c), \frac{1}{2} n(\beta-c)\right]$.

By the reasoning used in Case II, it takes a single experimentation to transit from monomorphic states with price lower then $c+\frac{2 \tau}{3 n}$ to the monomorphic state with price $c+\frac{2 \tau}{3 n}$. Under complete observability, it is possible to transit from states with price in the interval $\left[c+\frac{2 \tau}{3 n}, p^{c}\right)$ to the state where all firms choose $p^{c}$ when two firms experiment with $p^{c}$. By Remark 11, this is possible under incomplete observability as well. On the other hand, if the price in the initial monomorphic state is higher than $\beta-\frac{\tau}{2 n}$ and a firm experiments with $\beta-\frac{\tau}{2 n}$, it is most profitable. Here, firms do not compete for the marginal consumer. Therefore, the profit function is $2(p-c) \frac{\beta-p}{\tau}$ and it is decreasing in $p$ if $p \geq \frac{\beta+c}{2}$ (under our assumption on transportation cost, $\left.\beta-\frac{\tau}{2 n}>\frac{\beta+c}{2}\right)$. So, not only is the price $\beta-\frac{\tau}{2 n}$ imitated in the first wave of imitation but by Remark 10, the price spreads to the entire population. Now, from monomorphic states with price in $\left(\frac{2 \beta+c}{3}, \beta-\frac{\tau}{2 n}\right]$, if two firms who are most distant experiment with any price in $\left[p^{c}, \frac{2 \beta+c}{3}\right]$, then the experimenting firms are the most profitable.

\footnotetext{
${ }^{42}$ It may be seen that these two conditions are incompatible not only under the current restriction on $\tau$ but also when $\tau<\frac{2}{3} n(\beta-c)$ (where $p_{\text {nash }}=c+\frac{\tau}{n}$ ). Further, we can replace $p_{n a s h}$ by any $p \in\left(p^{\prime}, c+\frac{2 \tau}{n}\right)$ to say that if the initial state has price $p$, and two firms experiment with the same price $p^{\prime}<p$, then the experimentation will not be successful.
} 
This is because $\pi(p, p, p)>\pi\left(p, p^{\prime}, p\right)$ (the non-experimenting firms receive one of these two profits) and $\pi\left(p^{\prime}, p, p\right)-\pi(p, p, p)=\frac{1}{\tau}\left(p^{\prime}-p\right)\left(c+\frac{\tau}{n}-p^{\prime}\right)>0$. With the first wave of imitation the only firms that remain with price $p$ (at most four firms dispersed in two blocks of two firms each) obtain a profit of $\pi\left(p, p^{\prime}, p\right)$. It follows that $\pi\left(p^{\prime}, p, p\right)-\pi\left(p, p^{\prime}, p\right)>0$, and the remaining firms imitate $p^{\prime}{ }^{43}$ Thus, it takes at most two experimentations to transit to the set of monomorphic states where the price lies in $\left[p^{c}, \beta-\frac{\tau}{2 n}\right]$.

Next we will argue that it takes more than two experimentations to exit the set of monomorphic states where the price lies in $\left[p^{c}, \frac{2 \beta+c}{3}\right]$. First, note that it has been shown (in the proof of Proposition 3, statement (d), part (v), Step (1)) that a single experimentation is not successful under complete observability. By Remark 7, it is also unsuccessful under incomplete observability. So, we consider two-firm experimentations, and as argued, we focus on the two experimenting firms being neighbours. Suppose that when two neighbouring firms experiment, the experimenting firm is the most profitable firm and has a price lower than $p \in\left[p^{c}, \frac{2 \beta+c}{3}\right] .{ }^{44}$ It is imitated in the first imitation wave. Then, by what we have shown earlier (i.e. by Footnote $\left.42, \pi\left(p^{\prime}, p^{\prime}, p_{\text {nash }}\right)-\pi\left(p_{\text {nash }}, p_{\text {nash }}, p_{\text {nash }}\right)<0\right)$, the state reverts to one where all firms choose the price $p$. On the other hand, we have shown in the complete observability case that it is not possible for two firms to experiment into a state where the price is higher than $\frac{2 \beta+c}{3}$ under complete observability (recall Footnotes 30, 32 and 33). By the same reasoning as in Remark 7 , it is not possible for a higher price $p \in\left[p^{c}, \frac{2 \beta+c}{3}\right]$ to spread over the entire population, even under our observability structure. This shows that the stochastically stable set is contained in the set of monomorphic states where the price lies in $\left[p^{c}, \frac{2 \beta+c}{3}\right]$ (call this set $\Omega$ ).

We will finally show that it is not possible to transit from one state in $\Omega$ to another state in $\Omega$ with one experimentation but it is possible to do so with two experimentations. First, when the price of the initial monomorphic state equals $p \in\left[p^{c}, \frac{2 \beta+c}{3}\right]$ and a firm experiments with $p^{\prime}<p$, then we will show $\pi\left(p^{\prime}, p^{\prime}, p\right)<\pi(p, p, p)$, so that by Remark 10 , a reversion to the state with price $p$ occurs.

$$
\pi\left(p^{\prime}, p, p^{\prime}\right)-\pi(p, p, p)=\left(p^{\prime}-c\right)\left(\frac{1}{2 n}+\frac{p-p^{\prime}+\frac{\tau}{n}}{2 \tau}\right)-(p-c) \frac{1}{n}=\left(p^{\prime}-p\right)\left(c+2 \frac{\tau}{n}-p^{\prime}\right) .
$$

This expression is negative as $\left(p^{\prime}-p\right)<0$ (by assumption) and $\left(c+2 \frac{\tau}{n}-p^{\prime}\right)>0$ (as all prices in $p^{\prime} \in\left[p^{c}, \frac{2 \beta+c}{3}\right]$ and prices lower than that are less than $\left.c+2 \frac{\tau}{n}\right)$.

On the other hand, suppose that the price in the initial monomorphic state equals $p \in$ $\left[p^{c}, \frac{2 \beta+c}{3}\right]$ and a firm experiments with $p^{\prime}>p$. We will show that this experimentation is

\footnotetext{
${ }^{43}$ This two firm experimentation also shows that it is possible to transit from one state where price is in $\left[p^{c}, \frac{2 \beta+c}{3}\right]$ to another state with a lower price in the same interval.

${ }^{44}$ By Remark 4, Remark 5 and Remark 6, the experimenting firm with the lower price is the more profitable experimenting firm. Here, by assumption, it is also the most profitable firm.
} 
unsuccessful as $\pi\left(p^{\prime}, p, p\right)<\pi\left(p, p, p^{\prime}\right)$, and so a transition to another state does not happen.

$$
\pi\left(p^{\prime}, p, p\right)-\pi\left(p, p, p^{\prime}\right)=\left(p^{\prime}-c\right) \frac{p-p^{\prime}+\frac{\tau}{n}}{\tau}-(p-c)\left(\frac{1}{2 n}+\frac{p^{\prime}-p+\frac{\tau}{n}}{2 \tau}\right)=\left(p-p^{\prime}\right)\left(2 p^{\prime}+p-2 \frac{\tau}{n}-3 c\right) .
$$

This expression is negative as $\left(p-p^{\prime}\right)<0$ (by assumption) and $\left(2 p^{\prime}+p-2 \frac{\tau}{n}-3 c\right)>0$ since $p, p^{\prime} \geq c+\frac{\tau}{n}$. Thus, a single experimentation does not cause a transition from one state in $\Omega$ to another state in $\Omega$.

Finally, we will show that such transitions are possible with two experimentations. We have already demonstrated the transition to states with a lower price (recall Footnotes 43 ). Therefore, we focus on transitions to states with a higher price. In the complete observability case, the only type of two-firm experimentation that results in a higher price being imitated is where one firm experiments with $p^{\prime} \in\left(p^{c}, \frac{2 \beta+c}{3}\right]$, and the neighbouring firm experiments with a price that is high enough so as to give it zero demand. If the same experimentation occurs with incomplete observability, then a subset of the firms imitate $p^{\prime} \in\left(p^{c}, \frac{2 \beta+c}{3}\right]$. These firms receive either $\pi\left(p^{\prime}, p^{\prime}, p\right)$ or $\pi\left(p^{\prime}, p^{\prime}, p^{\prime}\right)$, with $\pi\left(p^{\prime}, p^{\prime}, p\right) \leq \pi\left(p^{\prime}, p^{\prime}, p^{\prime}\right)$. The other firms receive $\pi\left(p, p^{\prime}, p\right)$ or $\pi(p, p, p)$, with $\pi\left(p, p^{\prime}, p\right) \geq \pi(p, p, p)$. It can then be seen that

$$
\pi\left(p^{\prime}, p^{\prime}, p^{\prime}\right)-\pi\left(p, p^{\prime}, p\right)=\left(p^{\prime}-p\right)\left(c+2 \frac{\tau}{n}-p\right)>0
$$

By successive imitation, all firms imitate $p^{\prime}$. So, it takes two experimentations to transit between any two states in $\Omega$. Hence, all states in $\Omega$ are supported in the long run.

Case IV: $\tau<\frac{1}{2} n(\beta-c)$.

The Nash equilibrium price is $c+\frac{\tau}{n}$, and we show that the Nash state is the stochastically stable set. Using the same arguments in Case III above, it takes two experimentations to enter the Nash equilibrium state. But, as it is not possible to exit the Nash equilibrium state with two experimentations under complete observability, it is not possible to do so even under incomplete observability. This proves that the Nash equilibrium state is the stochastically stable state. 